\title{
MIGUEL EGUAL, POETA Y TRADUCTOR (I). EPISTOLARIO
}

\author{
Pasqual MAS I USÓ y Javier IELLÓN LAHOZ
}

Miguel Egual nació en la Villa de Almazora en la segunda mitad de 1680 o la primera mitad de 1681, y murió en Pego el Jueves 28 de junio de 1742 a los 62 años de edad.

Las primeras noticias sobre este poeta y traductor almazorense aparecen en la recopilación biográfica y bibliográfica de Vicente Ximeno quien, brevemente, nos dice de Egual:

«Miguel Egual, natural del Lugar de Almazora, vecino, y Fiscrivano Real, y del Ayuntamiento, y Sala Capitular de la Villa de Oliva, y hombre versado en la lengua Italiana, y bien instruido en la propiedad de la Española. Traduxo del Idiona Toscano un libro con este título:

I. Declamaciones Geniales, su Autor Juan Francisco Loredano, Noble Veneciano. En Valencia por Antonio Bordazar 1731. en 8. Avía traducido felizmente todas las Declamaciones; pero en la Inpressión onitió las dos de Antonio Caracala amante, y de Frine Lasciva, porque como dice en el Prólogo, antepuso sus christianas obligaciones a la gloria de Traductor de todas ellas. A lo último de cada Declanación añade de styo un Soneto sentencioso, y grave. Todos llegan a veinte y dos»'.

Los siguientes historiadores literarios de los siglos XVIII y XIX no citan ya a Miguel Egual, y tan sólo Fernando Mundina, a finales del XIX, le cita para-

1 Vicente XIMIino, Escritores del Reyno de Vatencia Chronológicamente ordenados deste el año MCCXXXVII de la Christiana Conquiste de la misma Ciudad, hasta el de MDCCXIII, Valencia, Esteban Dolz, MDCCXLVII, pág. 229. 
Praspando a Vicente Ximeno, y sin mencionar el hecho de que Egual suprimitera dos Deckanaciones en la edición de su traducción ${ }^{2}$. Posteriormente Enrique Beluán Manrique parafrasea a Fermando Mrundina, cambiaudo tres palabras". Y, mas tarde. Juan Blay Navarro resume lo poco que aportó Vicente Ximeno y lo incluye en su lista de personajes célebres de Oliva, olvidando mencionar su nacimiento en Almazora".

Ultimamente, intentando actualizar las inclinaciones literarias de Miguel Egual y basándonos tumbién eu las informariones de Ximeno, publicamos una breve reseña a la que añadimos la edición del soneto quinto de la primerá parte del libro del poeta almazorense". Todavía cutonces los daus sobre Miguel Egual se resistían a aparecer, pero la investigación segúa y no tardamos en encontrau algunos que iban a ser fundamentales. Nos reforimos a las cartas manuseritas y firmadas por el propio Miguel Egual dinigidas a su anugo y gran intelectual del siglo XVIII Gregorio Maýáns y Siscar. Y, además, otro hatillo con algumas cartas entre Juan Antomio Egual, hijo del almazorense que nos ucupa. y el citado intelectual. Les earlas se encuentran repattidas entre la Biblintea Serrano Morales 7264-17(a-15), 3962-3098, incluyendo un memorial, y cl Archivo del Colegio del Patriarea B.A.H.M. domde encontramos dos raclas en latín además de otros textos referidos a Miguel Égrual, pero ya publicados en las Declamaciones Geniales."

Miguel Egual se traslada dé Almazora a Valencia para llevar a cabo sus esudios de escribano, según él mismo nos cuente refiriérdose a su juventud: « Este Reino, o de su Capital, en donde he pasado la flor de mis años, con mis pocos estudios» (carta XIV). El 8 de abril de 1725 entra, con el salario de. 100 libras al año y sucediendo a Pedro Climent, en el cargo de Secreiario y Contador de la villa de Oliva. Fjerce este lrabajo hasta el 31 di: diciembre de 1730, aunque sigue vinculado al Ayuritamiento cle esta villa hasta junio de 1734, fecha en la que se retiró a su residencia de Pego. A Oliva había jo Miguel Egual con su mujer Josefa y su hijo Jutu Antonio de trece meses. Y al año siguiente, 1726, luvo su primera hiju. Como complemento a sus labores do se-

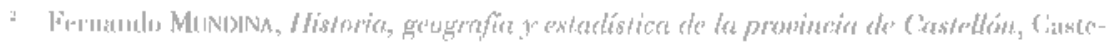
llón, 1873, pág. 57.

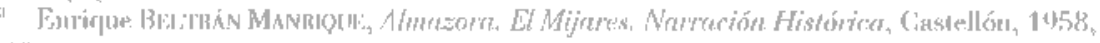
J自然. $\$ 318$.

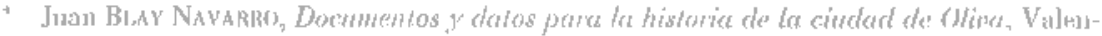
cial Eeir, 1960) púg. 71.

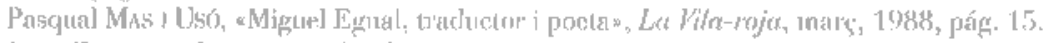

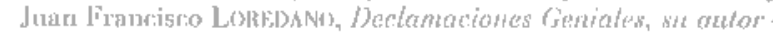

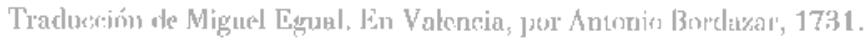


cretario, en 1726 elaboró un plano de los habitantes de Oliva señalando las rentas que se formalizaban en la villa cou cargos y obligaciones en las transferencias.

Estuvo presente en 1727, segúm un documento conservado en el Archivo Parroquial de Oliva, en su Junta General para tratar del derribo de la iglesia vieja, y de proseguir la fábrica de la nueva, el 23 de noviembre de 1727.

Posteriormente, en 1728, realizó la liquidación de las deudas atrasadas del ayuntamiento, anotadas año por año, porque hasta ese momento se realizaban las transferencias "a mente».

Durante 1729 anduvo ocupado recopilando las deudas atrasadas desde el principio de la guerra hasta el año 1725. Esta tarea le entretuvo durante cuatro meses. En octubre del mismo año, Gregorio Mayáns le encarga la dirección de un sobrino del rector de Pavías para la práctica de escribano, tarea que Miguel Egual se esforzó en llevar a cabo en Oliva. Mayáns, como prueba de agradecimiento, le rnvía Las Gterras de Grantada de Diego Hurtado de Mendoza, pero como su deseo es profundizar en el estudio de la lengua española pide a Mayáns la Orlografía y Apología de Antonio Bordazar, libro que fue muy discutido cn la época y que, a pesar de su poco rigor científico, Mayáns prologó a su amigo Bordazar.

En 1730, por orden de Intendencia claboró, durante tres meses, el censo de la villa de Oliva y realizó el padrón con los capitales de cada vecino. En diciembre del mismo año, la traducción de las Declamaciones Geniales está terminada y a punto de ser publicada. Miguel Egual parece no estar preocupado por la publicación de su obra; sin embargo, envía recado secreto a Mayáns diciéndole que si ha de alargarse al librero un doblón en oro para papel puede facilitarle la empresa. «Daré orden para que se entregue a Vm. al primer aviso, aunque deseo que esto quede privadamente entre los dos" (carta II). A finales de enero de 1731, por medio de D. Francisco Pasqual, pariente de Gregorio Mayáns, le envía el dinero para el impresor Roveda (carta III). Ya en estos momentos ha sufrido el revés de la censura, pues el doctor Albiñana no está conforme con que se editen las traducciones de las Declamaciones de Antonio Caracala y Frine Lasciva. Más tarde, Miguel Egual dirá que «las dos Declanaciones de Antonio Caracala i Frine, las he omitido por más que sea lo mismo que quitarle a Virgilio el libro quarto [la comparación no deja de ser asombrosa], i haya corrido felizmente la pluma en sus traducciones. Pero antepuse, como devo, mis Christianas obligaciones a la gloria de Traductor,... (Prólogo). 
Dos meses después, Gregorio Mayáns le sugicre la idea de dedicar las Declamaciones Genirales al consejero de su majestad, don José Bermúdez, propuesta que Miguel Egual acepta y le parece muy acertada porque, como él mismo dice en la dedicatoria refiriéndose a José Bermúdez, «los que tienen noticia de V.S. (i, ¿̨quién ai en España que no la tenga?) de su gran literatura, i erudición, de su eloquencia, afabilidad, prudencia, i demás partes, que coustituyen un Cavallero a todos visos grande, i digníssimo de singular veneración ». Más tarde, Miguel Egual intentará en varias ocasiones sacar partido de esta descripción la udatoria de don José Bermúdez. Es también por estas fechas cuando, por medio de Francisco Pasqual, hace llegar a Gregorio Maýán 26 reales más (carta VH) para pagar a los oficiales de impresión que están llevando a cabo su oficio con la traducción de Miguel Egual.

Durante 1730 hubo de verse envuelto en algún problema administrativo, pues en abril de 173.1 escribe; El correo passado oscriví à su Excelencia satisfaciendo a los cargos simiestramente hechos; espero su resulta para sacrificarme hasta lograr salir de aste Argel, j conseguir mi quietud, que es lo que me conviene» (carta VII). La preocupación sigue en junio del mismo año cuando encabeza una carta diciendo: «Mui señor mío i amigo. Preocupado de la tropelía de mis cosas (por no decirlo de otra manera) " (carta VIF); y parece que en octubre ya ha cesado el acoso a su persona, pues señala que «aora en este rincón. en dornde todo el Comercio se reduce a tratar de Amarjales, i terones» (carta IX). Posiblemente los quebraderos de cabeza desaparecieron unos meses antes, cuando a linales de junio se trasladó a su residencia de Pego, donde según afirma: "Yo me esfuerzo a vivir en la funesta rustiquez de este sitio, i a no tener alguna propensión a los libros, creo, que ya no supier'a hablar en español» (carta IX).

Poco sałemos de Miguel Egual durante 1732, año en el que estuvo ocupado en la traducción del italiano de un nuevo texto. Pero esta vez corrió peor suerte con la censura y, en carta del 28 de marzo de 1733, apunta: «sin duda deve estar estragado el estómago de esse buen viejo, o no há leído bien cl originál italiano, pues el estilo de éste ya dije a Vm. que era mui llano i que nue sería fácil subirle de punto» (carta $X$ ): y más adelante: «Pues nada se pierde cn no imprimirse la traduceín, sí sólo el provecho comúr de tan divina Historia, Sírvase Vm. retírarla, i guardármelà, como preciosa joya» (carta X). Láuentablemente no sabemos de qué obra se trata al no imprimirse la señalada traducción y perderse el manuscrito. Como afirma el propio Egual por estas fechás, el duro revés de la censura lo supera disfrutando de la lectura de El Orador Cristirno, obrá que Gregorio Mayáns, su autor, le había regalado.

En 1734 entra en conflicto con los gobernantes de Oliva, ya que según un 
memorial que se le exigió, Miguel Egual resultaba acreedor del Ayuntamiento. El doctor Pont es el intermediario en este asunto y le advierte que *lo havía comunicado con el Ayuntamiento i que los del Govierno estavan en malíssima disposición, i que le parecía más conveniente el que yo (Miguel Egual) cejara, que no llegara a pleito, pues con el pretexto de defender al Común, me pondrían en un laberinto» (carta XII). A este propósito, asegura que «hice refección de que los que componen el Govierno son los que fraguaron mi emulación, i que era mui posible llevassen adelante sus ideas maliciosas, por lo que me pareció condescender en ajustarme por medio del mismo Dotor Pont, quien lo ha egecutado mui a satisfacción de tal Villa, i con mucho detrimento míos (carta XII). En las sucesivas cartas a Mayáns aflora su malestar por causa de este asunto, y así manifiesta que «todos conocen el agravio que se me hace; pero en llegando al remedio nadie le practica, tanto puede la ceguedad de la envidia» (carta XIII). Y eso que la suma que se le debe no es excesiva, anécdota que le hace incluso decir irónicamente que «todo mi perjuicio viene a reducirse a unos ciento o, a lo más, 150 pesos; i según se explicava esta gente, tomando por pretexto el beneficio común, podían maliciosamente acarrearme $150 \mathrm{mil}$ pesadumbres. Dios les haga mucho bien, i dé luz para governar con más justicia» (carta XIII).

Sobre este acontecimiento, ya en carta del 10 de abril de 1734 , pedía a Mayáns que informara de su caso a don José Bermúdez, consejero y fiscal real y procurador del Infante don Carlos, y, en una carta siete días después, insiste en el deseo de que se informe a José Bernúdez para que éste interceda en su caso. Ese mismo año quedará resuelto el asunto para volverse a retirar a Pego, «en donde -dice- me hallo con mi familia desde el 6 del corriente» y, más adelante, hablando de Pego dirá que acsta villa es algo menos racional que Oliva, pero lo que le falta de racionalidad, tien más de libertad y quietud (carta XIV). A partir de ahora todas las cartas las envía desde Pego.

El día 3 de julio de 1734 Mayáns le ofrece ser contable del Duque de Medinasidonia, tarea que Miguel Egual declina, según informa, "por hallarme con las fuertes amarras de tres hijos i mi parienta en cinta: el mayor que es Antonio de diez años i de las dos niñas, la mayor de ocho. Familia que totalmente embarazaría el transplantarme en essa Corte, sino con gran incomodidad, i a mucha costas (carta XV). Aunque él se siente fuerte a sus 53 años señalándolo de este modo: "por hallarme con ardor, i espíritu para esse, i qualquier otro encargo» (carta XV). No obstante, Miguel Egual pide a Mayáns otro tipo de empleo: «Por si fuese tal mi Fortuna, que los mismos favores de Vm. pudiessen dirigirse a las Conveniencias de este Reino, o de su Capital (...) con mis pocos estudios, hallaría el corregimiento de mi deseo, i fácil salida a tanto repasso. En aquella (se refiere a Valencia) hai muchos empleos, assí Reales, como de la In- 
quisición, i de Señores de essa Conte, que tienen sub Estados en csro Reino, capaces para vivir con gusto, i conveniencia. Si esto fuere dable lo suplico a VIn. ya que directamente me hallo sin méritos para insinuárselo al Sr. Don Joseph Bermúdez, i sólo Vm. puede. como hasta aora, suplir mi demérito» (carta XV). Sin embargo, estos ruegos no fructificaron.

A finales de 1734 tuvo motivos para alegrar su tranquila vida en Pego al ver publicada una carta suya en latín, con su correspondiente contestación, eu el libro de Cregorio Mayáns Cartas mornles, militares, civiles, i liferarias. Miguel Egual conenta al respecto: "Yo he quedado corrido de leer mi nombre, con mi propia Naturaleza, i entre tantos literatos» (carta XVI).

Duraute 1735 sigue residiendo en Pego bastante a disgusto, pues afirma que "yo vivo a lo rástico en este páramo, pero siempre con las constantes esperanzas de salir de él». Y deste esta villa se ocupa de algunos negocios administrativos de la familia Mayáns, realizando un viaje a Jávea el 10 de junio para recoger una escritura concluida el día anterion a favor de Gregorio Mayáns y Siscar.

En noviembre de 1735 se siente orgulloso de su hijo Juan Antonio prorgue «ya compiezu a construir Concilio i Breviario, pero como es tan muchacho, que hará los doce años al nuazo que viene, hago enenta de no estrecharle pues tendrá tiempo para todo» (carta XX). Y a finales de año siguiente comenta Miguel Egual sobre su hijo: "ya empieza a vertir a Cicerón, i para el octubre que viene hago cuenta saldrá a Filosofía» (carta XX[I).

La actividad de Miguel Lgual en 1737 se centra cr solucionar los problemas de su sobrino Basilio Clausell, hijo de su hermana, el cual había estado siete anos dre pretendiente en Roma y había conseguido dos beneficios, uno en Benicarló y otro en Baltea, pero el Obispado de Tortosa no le pernitía que ocupara su cargo, a pesar incluso de las Bulas despachadas en Roma. Las órdenes reales dictaban que se necesitaba el permiso del fiscal del Consejo Real, y por ello Miguel Egyal solicita a Gregorio Mayáns que comunique este ásunto a losé Bermídez y así se solucione el problema.

A lo largo de 1738 Miguel Egual padece una grave enfermedad en la que le dieron por muerto, aunque las secuelas fueron simplemente una «destilación que - dice Egual- en llegando a destemplarme la cabeza, no puedo ver libro, ni pluma» (carta XXVI). De este año no se conoco carta algura, debido a la enfermedad de la cual se desprendió como consecuencia que su hijo, no pudiera esudiar lo que deliera, pues como explica Miguel Egual: «me ha sido preciso retenerle en casa hasta resolver sobre su destino. El mí́o por ahora es hacerle Écle- 
siástico, sea como fucre, i si él desea lo mismo, pues considero, que con este estado, quedarán sus hemmanitas más abrigadas, y mi vejez, será más llevadera» (carta XXVI).

En 1739 tuvo ocasión de volver a entrevistarse con Gregorio Mayáns al regreso de este último a Oliva, al cual no había visto desde que se marchó a la Corte. El 13 de septiembre del mismo año concierta otra cita con Gregorio Mayáns para el miércoles 16 y poder visitar la biblioteca que se había traído a Oliva. El día 21 del mismo mes concierta otra cita con Gregorio Mayáns para que le cnseñe la librería a su hijo Juan Antonio.

En los años siguientes las cartas entre Miguel Egual y Gregorio Mayáns son simples felicitaciones navideñas. En la última del 3 do enero de 1742 cuenta que ha solicitado ayuda a don Pedro Pasqual, tío de Gregorio Mayáns, para conseguir un beneficiado en la Iglesia de Pego para su hijo Juan Antonio. En la misma carta pide a Mayáns que haga de intermediario, nuevanente, con don José del Ciampillo, al mando del Amirantazgo, cn el que existe una plaza vacante en la Capellanía Regular de las Caleras de España, cargo que pretende preferenremente Miguel Egual para su hijo Juan Antonio, el cual acabó ejerciendo de escribano público y notario en la ciudad de Valencia.

La primera carta que escribiera Juan Antonio Egual a Gregorio Mayáns fue para comunicarle la muerte de su pade cl día 28 de junio de 1742. Posteriormente, siendo ya Juan Antonio Escribano y Notario en Valencia, realizó en Pego una copia del protocolo del deceso de su padre con fecha de 18 de septiembre de 1747, y la copia, que se conserva en Archivo Parroquial de Santa María la mayor de Oliva, es del 23 de diciembre de $1772^{7}$.

? Juan Antonio EcatAl, Cartas, BSY: 7264-17 (A-15); 3962-3900. 
EPISTOLARIO

MIGUEL EGUAL - GREGORIO MAYÁNS

CRONOLOGÍA DE LAS CARTAS

\begin{tabular}{|c|c|c|c|c|c|}
\hline$N^{n}$ & $\mathrm{D} \hat{A}_{\mathrm{A}}$ & MES & $\mathrm{AN} O$ & & SIGNATURA \\
\hline I & 10 & vetulyte & 1729 & & $3967 *$ \\
\hline II & 23 & diciembre & 1730 & & 3984 * \\
\hline III & 20 & enero & 1731 & & $3985^{*}$ \\
\hline IV & 3 & febrero & . & & $3986^{*}$ \\
\hline V & 12 & abril & s & Epist. lib. VI** & \\
\hline VI & 6 & abril & * & " * & \\
\hline VII & 21 & abril & , & & $3987^{*}$ \\
\hline VIII & 2 & junio & . & & $3977 *$ \\
\hline IX & 28 & octubre & • & & 3979 \\
\hline $\mathrm{X}$ & 28 & marzo & 1733 & & $3988^{*}$ \\
\hline XI & 9 & mayo & . & & $3989^{*}$ \\
\hline XII & 10 & abril & 1734 & & $3971^{*}$ \\
\hline XIII & 17 & abril & , & & $3973^{*}$ \\
\hline XIV & 17 & junio & , & & 3990 \\
\hline$X Y$ & 24 & julio & , & & 3991 \\
\hline XYI & 20 & noviembre & " & & 3992 \\
\hline XVII & 1 & abril & 1735 & & 3993 \\
\hline XVIII & 18 & abril & , & & 3994 \\
\hline XIX & 24 & junio & $"$ & & 3978 \\
\hline $\mathrm{XX}$ & 27 & noviembre & , & & 3995 \\
\hline XXI & 16 & diciembre & " & & 3981 \\
\hline XXII & 15 & diciembre & 1736 & & 3980 \\
\hline XXIII & 25 & enero & 1737 & & 3982 \\
\hline XXIV & 16 & agosto & $>$ & & 3996 \\
\hline XXV & 20 & diciembre & + & & 3997 \\
\hline XXVI & 19 & enero & 1739 & & 3975 \\
\hline XXVII & 19 & agosto & , & & 3983 \\
\hline XXVIII & 13 & septiembre & , & & 3998 \\
\hline XXIX & 21 & septiembre & , & & 3976 \\
\hline XXX & 29 & diciembre & . & & 3974 \\
\hline XXXl & 22 & diciembre & 1740 & & 3972 \\
\hline XXXII & $\rightarrow$ & diciembre & 1741 & & 3969 \\
\hline XXXIII & - & enero & 1742 & & 3970 \\
\hline
\end{tabular}

Las cartas con * proceden de Oliva; con ** de Valencia (de Mayáns a Egual), y las demás de Pego. Las cartas V y VI (con error de datación en el original) se hallan en el Archivo del Colegio del Patriarca de Valencia: BAHM, y las demás en la Biblioteca Serrano Morales de Valencia. 
"Mui S* mío. Para lo mucho que deseo servir a Vm. es nada el encargo que Vm. me hace, de la dirección del Sobrino del Retor de Pavías para la práctica de Escrivano. Aquí, aunque es frecuente el tropel, no son las dependencias continuas; pero procuraré desempeñar la Confianza que a Vm. le devo, i que logre su aprovechamiento el recomendado.

$\mathrm{D}^{s} \mathrm{~g}^{\text {te }}$ a $\mathrm{Vm}$. los $\mathrm{m}^{s} \mathrm{a}^{9}$ que les ruego. Oliva, y Octubre 10 de 1729.

$$
\begin{aligned}
& \text { B.L.M.de Vm. } \\
& \text { Su m ob } \text { b }^{\text {the }} \text { i Am } \\
& \text { Miguel Egual } \\
& \text { Sr D" Greg }
\end{aligned}
$$

«Mui S ${ }^{a r}$ mío. Aprecio sumamente la fina expresión que Vm. me hace de Pasquas i con igual fineza deseo que Vm. las logre mui felices, en compañía de sus $\mathrm{S}^{\text {whe }}$ Hermanos, a quienes repito mi verdadera oblig".

Agradesco a Vm. Las Guerras de Granada de D. Diego de Mendoza, que siendo un perfecto egemplar de la pureza de la Lengua Española, como Vm. dice en su Discreta Aprobación, veo en esta más dulcem practicada aquélla, que en lo principal de la obra, eficaz argumento de la gran comprehensión que Vm. ha logrado de la propiedad de nuestra lengua. I pues Vm. sabe enriquecerme de tantas i tan curiosas erudiciones espero lograr las de la Ortografía i Apología de D. Antonio Bordazar, en que no dudo, tendrán decoroso empleo la enseñanza i el gusto.

Sobre mi traducción confiesso deviera servirme de impulso la Aprobación de Vm. i de Bordazar, para que saliese a la luz, pero me contentaré en que haian corrido por medio del favor de $\mathrm{Vm}$. las diligencias; i si ha de alargarle al librero un Doblón en Oro para papel puede facilitarle la empresa, daré orden para que se entregue a $\mathrm{Vm}$. al primer aviso, aunque deseo que esto quede privadamente entre los dos.

Saludo a sus $\mathrm{s}^{\text {rs }}$ Hermanos, i ruego a $\mathrm{D}^{6} \mathrm{~g}^{\text {de }}$ a $\mathrm{Vm}$. los $\mathrm{m}^{*} \mathrm{a}^{y}$ que deseo. Oliva i Dez. 23 de 1730

B.L.m. de Vm.

$\mathrm{Su} \mathrm{m}^{s}$ fino $\mathrm{s}^{\mathrm{tor}}$ i $\mathrm{Am}^{\circ}$

Miguel Egual

S D" Grer ${ }^{\circ}$ Mayáns, i Siscar, m. s. m.» 
"Mui S" mío su Par" D" Fran" Pasqual mi Amigo, i Sor entregará a Vm, las 20 el para Roveda; Vm. se servirá entregarlas cómo i quándo le pareciere. Me alegro que el original italiano quede en poder de Vm. con lo que se mejorará qualquier cláusula que no tuviese la eficacia i sentido correspondiente, pues ya sabe $\mathrm{Vm}$. que Yo no le di la última mano a la traducción, con el fin de imprimirse como ahora sucede, $i$ aliquando domitat itomenis, pero me sosiega la confianza de $\mathrm{Vm}$.

Veo el reparo del D' Alhiñanı solsre la 3 Declamación de: Antonio Caracalla i él mismo encontrará en lá 11 de la 2 parte, cuyo título es Fríne Lasciva, pues su fin es tentar la continencia de Genócrates. Yo amigo mío, no soi vhélogo para contrastar sobre este escrúpulo; mi intención es seguir lo más seguro, i no apartarme de lo que sintieren Hombres Doctos; i si no pudiera remedianne con quitar algunas dáusulas menos decentes, quíteme enteramente ambas Declanaciones i en la Ultima, que es de Genócrates Continente, repuesta a la de Frine, podrá mudarse alguna palabra para que no hagu relación al ser respuesta, con lo que se simulará lá falta. Verdaderam"es lástima que se omitan, pues ambos son un pasmo, o yo me engaño, i no lo entiendo, que pucde ser uno i otro; $\mathrm{i}$ aunque pudiera dar egemplarcs ( $\mathrm{V} \mathrm{Vm}$. muchos más que yo) de semejantes improsos, i aún más Vivos, siempre deseo, i devo sugetarme a lo más seguro, que para mí lo será siempre el dictamerl de Vm, en quien depongo gustosanente el mío, con lo que pudrá $V \mathrm{~m}$. guiarlo a su disposición.

Queda enmendado el Prólogo i la Dedicatoria la trabajaré un día de estos, i tudo lo inviaré a Vm. adelantado para que Vm. dé la última maro, con lo que

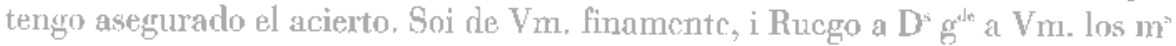
a" que deseo. Oliva, i Henero 20 de 1731.

No deje Vm. de leer con reflexión las 2 Declamaciones de Antonio i Frine que es cosa do media hora.

$$
\begin{aligned}
& \text { B.l.m. de Vill. } \\
& \text { Su m re } \text { i ob" }^{\text {tho }} \mathrm{s}^{\text {thl }} \\
& \text { Miguel Egual } \\
& \text { Sr D" Greg" Mayáns i Siscar," }
\end{aligned}
$$

\section{IV}

"Mui s" mís i Amigo. Celcbro mucho que la impressión corra sin tropiczo. Yo escribí a Vm, bajo Pliego del amigo, 5" D" Fran ${ }^{\text {w }}$ Pasqual, por medio de un 
Criado de Juan Bautista Ripoll, consultándole el estilo que havía sobre pedir el beneplácito a su Ex para la Dedicatoria, pareciéndome prevención precissa, e incluí un tanto de ella para que Vm. ingenuamente añadiesc, i quitase a su gusto; i segńn la que recibo de Vm. por el Correo; i no ha llegado a tiempo de responder por él, o se ha extraviado, i por si fuere lo segundo repito la Dedicatoria e incluio el Prólogo, en que igual mente espero dever a Vm. añara algo sobre la utilidad de las Declamaciones i lo disponga despóticamente a su satisfacción, con el seguro que lo será mía, en todos tiempos. La Crítica que hacía a lo último del Prólogo la he quitado, por no parecerme conveniente, i le finalizo con la modestia O que Vm. verá i assí estimaré a Vm. que quite de la copia de mi traducción totalmente el Prólogo que havía. Mucho tendrá que agradecer este Reino a la incansable aplicación de Vm. pues van reciviendo las Buenas I etras, que tiempo hace iacían en el sepulcro del olvido. Dios le dé a Vm. mucha vida para

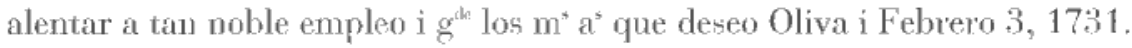

B.l.m. de Vm.

Su m. ren ${ }^{\text {it }} \mathrm{iob}^{\text {the }} \mathrm{s}^{\text {ilut }}$

Miguel Egual

S" D" Greg" Mayáns i Siscar. *

\author{
V \\ "MICHALIS EGUAL GREGORIO MAJANSSIO, Ge- \\ neroso, Antecessori Valentino, amigo suo exim- \\ mio, S. D.
}

Vehementer gaudeo Declamationum mearum censuram a Regio Castella Senatu tibi mandatum esse. Critici personam tantisper depone, \& amici utere. Omnes tui domestici bene valent. Ego quogue. Verum semones tuos amoenissimos valde desidero. Quoniam vero hanc jucunditatem mihi absentia ademit, si quando sum otiosus, scripta tua lectito: atque in Didaci Saavedre Panegyrico animadverti, te nominasse Balthasarem Gracianum, quem vulgus \& inscripti libri appellant Laurentium. Id ipsum cgo acceperam a clarissimo \& eruditissimo Viro Didaco Vicentio Fidania, magno Aragobia lumine \& ornamento. fama ne permotus, an aliquo testimonio id assereret, non memini. Cum autem tu eodem loco dicas CI. Virum Latentium Matthaum Sanctium in sua illa Crisi adversu Gratianum latuisse sub nomine Sanclii Terzonis Mole, retexi literas, \& latentem inveni veritatem. In Gratiano dispar successus. Quare rogo te, qua ratione nixus (neque enim dubito quin aliquam habueris) immutais nomina, ut si forte aliquis id reprehenderit, ego tueri possim. Præterea indica mihi quis au- 
tor fuerit Rhetorica illius Castellana anonyma, cui tu inter vernaculas aliquando pahnam dedisti. Rescribe etiam an censeas cervantem esse verum autorem Quixoti. In si occurrerent deceret, tua abuti patientia: nam proculdubio

In publica commoda peccem

Si longo sermone morer tua tempora Mayáns.

Vale literarum decus. Et me mutuiter ama. Oliva, XII. Kal. Aprilis, Anni MDCC:XXXI.

Illud in animo mihi f'edet inmotumeque est dedicare meam Declamationm Versionem CI. Viro Josepho Bermudetio Consiliario Reggio, cuius exiniam prudentiam, docriman, humánitatem, liberalitatem toties mihi pradicsti. Scio consilimm hoc tibi valde placiturum: adeo ut sententiam tuam exquirere non fit necesse. Iterum vale, s

\section{VJ \\ "GRE. MAJANSIUS MICHALI EGUALI, AMI co suo dulcissimo, S.D.}

Ponleelle mecum jocaris. Vis ut aljiciann personam critici, ut carn surnas. Anovi paullisper: non tamen abjeci. itaque legim Joannis Francisci Lauretani Declamationes in l lispamiam linguam a te conscrvas; fipigrammata etiam quat harum singulis addidisti. Vis ut candide proferam judicum meum? Melior es seriptor, quam interpres. Vel ut aliter dicam: Epigrcummate tua mihi magis placent, quam Declamationes illius. In his multa puerilia: in illis omnia viro digna. Tibi igitur sum autor, ut gravius argumentum suspicias, ut judicum tuum magis innotescat. Venio ad quæsita tua.

Critici Magni autor proculdubio fuit Balthasar Gratianus Jesuita. Ita censuit eruditissimus Nicolaus Antonius: rationem attulit nullam. Forte quia communis omnium opinio erat. Ego ei assentior his conjecturis nixus. Antonius Liperius Cilericus Regularis in Censura premissa prima Critici parti, alt legisse se librum Compositum a Patre Laurentio Gratiano. Quorsum illa Patris mentio nisi ut designaretur jesuita? Adde obiter illius Censuræ autorem ipsum esse Gratianum, ut stillus indicat plenus ingeniosis schematibus soni similis. Familiare id scriptoribus, a quibus Censores designati solent petere censuras, ut eis gratificcntur. Itaque non corum ambitioni, sed horum urbanitari imputandum est. Hoc ego obseravi in quampluribus scriptoribus, qui probe sciebant optimo vino non esse millibus Jo. Marianam, cuius prudentiam gravitatemque spirant 
judicia prafixa ommibus eius operibus. Ad Gratianum redeo. Secunda pars Critici magni, Laurentii Gratianï; tamen in Censura ei præposita (quam etiam puto scrpsisse eundem Balthasarem, \& edidisse sub nomine Francisci Andrece $U_{s}$ tarrozii, historici clarissimi, pretendentis ab eo aliquantulum dissentire, ut autorem se magis simularet) tribuitur Gracia cuidam de Matalones, homini in Republica literaria plane obscurissimo ignotissimoque. Unde clare liquet utrumque nomen Laurentï scilicet. \& Gracie suppositum esse. Atqui consta1 Gratianum queda, autorem fuise, ut patet ex censura critica josephi cuiusdam Longi (sub cuius etiam nomine latere voluit Jesuita ille) cuius postrema verba sun hac. omnia qua legi Frater Stephanus Sans, in censura præmissa tertia parti (quam, sicut \&.sequentem Alfonsi Munnozii Otalore etiam puto esse ciusdem Gratiani, non vero reliquas) ait autorem Herois, Politici, Diserti, Artis ingenü, \& Prima, \& Secunde partis Critici magni, eundem esse ac Tertice. At nisi me fallit memoria in Heroe prince editionis legisse memini acrostichidem quandam in quan legebatur nomen Balthasari Gratiani. Cui acrostichidi (ut hoc obiter addam) sunt simillima: quamplurima notatu dignissima, quas legere poteris in libro Castellanis versibus conscripto cui Titulus est, Aula Dei: ubi animadvertere poteris laudatorum quorundam malignitatem detestabilem. Rursus e diverticulo in viam. CI. vit Joannes Vicentinus de Lastanosa qui fuit amicissimus Balthasaris Gratiani, ut inter alia constat ex Secunda partis crisi secunda qua tota petinet ad celebranda miracula (Hispania loqui liceat anagrammatis caussa) de Salastano, id est, si literas invertis, de Lastanosa; Joannes inquam Vincentius de Lastanosa in Musceo numismatum Hispanorum incognitoum pag. 77. ita scripsit. Pater Balthasar Gratianibus Societatis jesu, Rector olim Collegï Tarraconensis, celebris ob artificiosa scripta, uti publice testantur, Heros excusus fexies in diversis regnis, Politicus Ferdinandus. Ars Ingenii Acuminis, alia uce habet prelo parala c. Adde eundem Lastanosam pag. 5. tribuere Balthasari gratiano Artem ingenii, qua tamen prodiit subnomine Lanentii sicuti Criticus Magnus. Hac si diligenter observassent qui in oratione mea incuriam meam reprehenderumt, non adeo pracipiti judicio usi fuissent. Saltem debebant, ut tu. modeste quarere a me rationem ob quam inveri nomina.

Autorem Rhetorica Castellanc, quam impense ante me laudavit vir clegantissimi ingenii Joannes Petreits Toletanus Latina epistola disertissima ei pramissa, existimo fuisse Michaelem de Salinas Monachum Hieronymianum eruditissimum. Aliquorum est haec opino, quam indicavit Nicolaus Antonius, \& libentissime probo.

Ad Quixotum, quod attinet, scio fictam illam Historiam ab aliquibus Philippo $\mathrm{W}$. Nullo certe neque indicio, neque judicio. Verissimus autor est Michael de Cervantes Saavedra. Rectius dubitare potuisses, quisnam fucrit autor illius 
secundi Quixoti, quem Cervantes in Prologo secundep partis, ait, genitum fuisse in oppido Tordesillas, natum Tarracone. Nimirum est Alphonsus Fernandez de Avellaneda ex oppido Tordesillas, qui impari ingenio, \& repugnantibus Musis ausus fuit publicare, vivo ipso Cervantes Contintationem Quixoti, eamque edidit Tarracone apud Philippum Robertum 1614, in 5.

Potuisse etiam dubitare de autore fabulce illins Anadisti Gaule quem librum equitum imaginariorum primum fuisse, qui in Hispania fuerit excusus, memorat Croctutes, haurmu rerum peritissimus in eruditissino illo cap. 6. Prima partis Quixoti. Stupenda lectionis vir Ant. Augustinus Dialogo 2. pag. 42. ait Lusitanos aflirmare quam credere potui, libellum inscripum EL LazariLo de Tormes, veram sobolem esse sapientissimi viri Didaci Mendoza. Potins assentior Fratri Josepho Seguntino Hieronmiano Monacho doctissimo dissertissimoque, qui in Historia Sodalitii Sancti Hieronyni Lib. 1. cap. 3.5. Libellim illum nibuit Fratsi Jounn Ortega Sodali sto. Neque mirum videri debet curcullatun dedisse operam huius scriptionis generi, propterea quod unc temporis apud Hispanos maxime invaluerat pestis illa fabulosorum librorum. Prospera

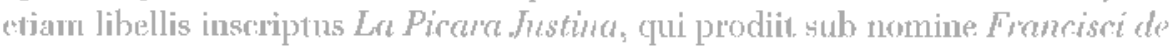
Ubeda dicitur esse proles Andrea Perezï Domínicami sodalis. Ea fama vagatur. Sed nittanus eiusmodi cruditionem, nam mihi videtur Attilius monere ada urem, Satius esse oriosum esse, quam nihil agere: \&, at Martilis noster difertissime dixit,

Turpe est diffiles habere nugas,

Et stultus labor est ineptiarum.

Consilium de tuo libello dedicando summo amico meo, \& probo, \& urgeo, \& ut id lasias olssignatis tabulis tecum agam. Neminem vidi qui sincerius quam ille amicitias colat, firmisque retineat. (ium his literis habebis judicum quod leci Lauretani tui. Cum argurentum gravius suspicies, te laudabo diligentius, \& pro tow merito. Da operant us valcas. Valentia. VI. Kal. Aprieis, Anni MDCCXXXI."

\section{VII}

«Mui $S^{m}$ mío, i Amigo. Ha sido noble pensamiento el de Vma an dedicar la obra a D" Josef Bermúdez; pues tengo bastantes noticias de sus singulares i nobles prendas. Recibí el Original manuscrito: i los dos pliegos últimos, que han completado un libro. Lá Dedicatoriá está como de Vm. que es cuanto puedo decir. Agradezco a Vm. infinito la puntual diligencia de la reimpresión del primer 
pliego, estimo a Bordazar su galantería, i va orden a D" Fran" Pasqual, para que entregue a Vm. los 26 reales, del trabajo a los oficiales, de que rindo gracias.

Me parece mui bien, que se imbien a Madrid los seis libros encuadernados en pasta, con la Carta que incluio para su soría que va tal qual está mi cabeza, i si Vm. no le parcciere bien, i huviere lugar podrá mejorarse. Al P. Retor Salvá se le deve dar a lo menos un libro, esso queda a dirección de Vm. como practico. Otro devo dar al D" Antonio Albert de Esparra, que es mui mi amigo; i después que Vm, tome los que quisiere a su Voluntad, i arbitrio, repasando a quien gustase; los que quedaren podrán ponerse en poder de 1)" Franco Pasqual para que en primer ocasión me les remita, i quede Vnı. libre de esta molestia.

Estimaré a Vm. se sirva escrivir algo a D" Joseph Bermúdez no sólo para que sepa de mí, sí para conciliar más su ánimo, con el favor de Vm. la advertencia al librero de que no parezea el primer pliego, es mui el caso, pues de lo sucedido no se ha de hacer mención por ningún resquicio. No dudo de la lei, i sangre que a Vm. le asiste, habrá sentido mi dolor en este desvío, i agradezco a $V m$. muchíssimo sus finas espresiones. El correo passado escriví a su Exa satisfaciendo a Jos cargos siniestrament" hechos; espero su resulta para sacrificarme hasta lograr salir de este Argel, i conseguir mi quietud, que es lo que me conviene, i servir a $\mathrm{Vm}$. en todos tiempos, con la más fina i constante voluntad.

$D^{*} g^{\text {ck }}$ a $V^{\prime \prime} \cdot m^{*} a^{\times}$que le ruego i he menester. Oliva, i Abril 21 de 1731.

$$
\begin{aligned}
& \text { B.l.m. de Vm. } \\
& \text { Su m ren }{ }^{\text {kn }} \text { i ob "ta } \text { g }^{\text {thr }} \\
& \text { Mignel Egual } \\
& \text { S'D" Greg" Mayáns." }
\end{aligned}
$$

\section{VIII}

"Mui S" mío, i Amigo preocupado de la tropelía de mis cosas (por no decirlo de otra manera) se quedó mi carta (respuesta a la que recibí por el Rector de Pavías) escrita sobre el Bufete de mi escrivanía. Vm. habrá disimulado mi omisión, y yo me acuso de ella, i aora digo a Vm. que recibí, por el mismo Retor, la Caja, regalo del S" Bermúdez, que verdaderament" es alaja preciosíssima, i todos los amigos la han celebrado mucho. Yo más que todos, porque me asegura su espresión, que en qual quier lanze egecutará este Cavallero los oficios de una ingenua galantería. Todo esto devo a la buena dirección de $\mathrm{Vm}$. a quien deseo complacer con inalterable afecto, i que gots Dios los $\mathrm{m}^{\star} \mathrm{a}^{\star \prime}$ que le suplico. Oliva i Junio 2 de 1731. 
B.L.m. de Vm.

Su $\mathrm{m}^{\mathrm{x}}$ fino, i oblig ${ }^{\mathrm{do}} 5^{\mathrm{t} \text { to }}$

Miguel Egual

S' D" Greg" Mayáns, i Ciscar mui s' mío."

IX

"Mui Sor mío, 1 Am". No estoi bien, sin saber de Vm. tanto tiempo, ni es razón, que $\mathrm{Vm}$. me prive del gusto que recibo, en las que sabe favorecerme; haciéndose más apreciables aora en este rincón, en donde todo el Comercio se reduce a tratar de Amarjales, i terrones. No es mi ánino distraer a Vm. de las serias ocupaciones en que le considero, sí sólo, el que en el corto espacio del desahogo, se acuerde Vm. de este Amigo, que apenas hai día que no piense en Vm., que nos desce sus aumentos; que aspire a tener ocasiones de servirle. Mi

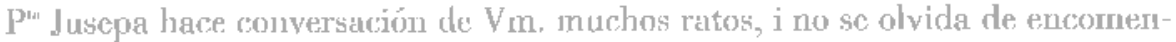
dar a Dios sus progresos. Mi Antonio bueno, i lo mismo las niñas. Yo me esfuerzo a vivir on la fumesta rustiguez de este sitio, i a no tencr alguna propensión a los libros, creo, que ya no supicra hablar en Lspañol. Feliz Vrrn. que goxa de la anable continua racionalidad de la Corté; cuins escollos, no dudo, habrá sabido superdirar la Prudencia. Deseo saber cómo la passa vm, en que obrase. emplear la pluma; i qué estado tienen esperamzas de sus afanes, pues qualquic-rál de estas noticias me servirá de su singular conferencia, i scrá para mí la mayor tener muchas ocasiones en que servir a V111. cuya Vida ge Dios los m" a" que le suplico. Pego, i octubre 28 de 1731.

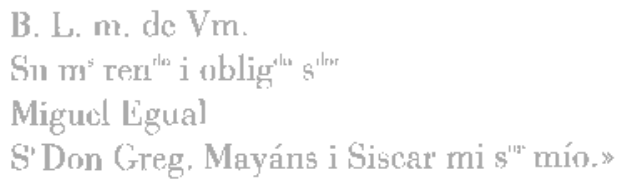

$\mathrm{X}$

"Mui S" mnío i Amigo. Por casa de su S" Padro de Vm. tengo noticia todos los correos de la buena disposición que a Vm le asiste, con lo que libro a Vm. de mis impertinencias. Ahora logre cl favor de Vm. en la que recibo, acompañada de la esperanza de ver luego impreso el Orador Christiano de que ya devo darme la enorabuena; pues aquí vi parte de él, la celebré como devía. Estoi bien seguro de que no me engañará la passión, porque sé mui bien, cuán substanciales son sus obras de Vm. 
Sin duda deve estar estragado el estómago de esse buen viejo, o no ha leído bien el original italiano, pues el estilo de este ya dige a Vm. que era mui llano i que me sería fácil subirle de punto; pero como esto no es propio del traductor le pareció a Vm., i a mí, devía correr con la misma sencillez, que por la sujeción, en lo más penoso de traducir i esto (aunque de passo) lo advertí en el Prólogo, para que no se me atribuyesse la bajeza de estilo.

Aseguro a Vm. que nada me ha alterado el desprecio de esse $\mathrm{R}^{\text {do }}$, pues aunque no son muchos mis años, tengo bastante experiencia de estos desvíos. A Monseñor Vidanía le sucedieron algunos que supieron sepultarle su modestia i silencio, i no dudo que a Vm. le habrán sucedido; pues Yo he llegado a rebatir puntos, sobre sus obras de $V \mathrm{~m}$. que no llegaron a lastimar, porque su fragua era la ignorancia, tales son los genios y humores de los hombres. Si me hallara en otro paraje, le hiciera saber a su $\mathrm{R}^{\text {th }}$ si posseo el dialecto Español, i qual es mi paladar; pero tráguese ahora el acíbar, que algún tiempo puede ser Tríaca. Pues nada se pierde en no imprimirse la traducción, si sólo el provecho común de tan divina Historia. Sirvase Vm. retirarla, i guardarmela, como preciosa joya, que el tiempo, i Yo para otros dos. Vm. se asegure que Yo vivo, i viviré eternamente obligado a la fineza con que Vm. se sirve tratar mis cosas, i deseo que Vm. conciba igual expresión en mi constante i fria voluntad para cuando sea de su mayor satisfacción, i ser Dios g' a Vm. los $\mathrm{m}^{*}$ a $^{4}$ que le suplico. Oliva i Marzo 28 de 1733.

\author{
B.l.m. de $V_{m}$. \\ Su m. ren ${ }^{\text {de }}$ i ob $^{\text {the }} \mathrm{s}^{\text {diar }}$ \\ Miguel Egual \\ S' D" Grego Mayáns i Siscar.»
}

\title{
XI
}

"Mui S" mío es de mi mayor aprecio el regalo del Orador Christiano, en que Vm. me favorece. Hasta aora sólo he podido leer la Dedicatoria, i la censurá del R"'n L. Cases; pero me ha bastado aquella para comprehender, que los juiciosos han de admirar la universalidad de Vm. en todo género de letras; i que los más provectos en la Oratoria, han de confessar el desengaño de su ignorancia. Vm. se ha hecho inmortal en esta obra; pues aunque en estos tiempos infelices, se hace poco aprecio de lo bueno: tengo por cierto, que la posterioridad celebrará lo que aora despreciarán, seguramente, los exentos de lección, i de noticias. Yo doi a $\mathrm{Vm}$. mil enorabuenas; i ruego a Dios dé a $\mathrm{Vm}$. mucha vida pára honrar nuestra Patria. 
Me ha gustado mucho la censura del P. Cases, i por más que lo ha pro curado, no ha podido ocultar las brillanteces de su estilo. Vm. procure descansar de sus tareas; i mandarme sin la menor ceremonia: pues le obedeceré con el gusto que devo. $\mathrm{D}^{\mathrm{s}} \mathrm{g}^{\mathrm{s}}$ a $\mathrm{Vm}$. los $\mathrm{m}^{*} \mathrm{a}^{*}$ Oliva, i Mayo 9 de 1733.

$$
\begin{aligned}
& \text { B.L.m. de Vm. } \\
& \text { Su } \text { m }^{*} \operatorname{ren}^{\text {lut }} \mathrm{i} \mathrm{ob}^{\text {the }} \mathrm{g}^{\text {tho }} \\
& \text { Miguel Egual } \\
& \text { S' D" Greg }
\end{aligned}
$$

\section{XII}

"Mui S" mío i amigo, después que justifiqué, uno por uno, los trabajos que representé en mi Memorial, me dijo el D' Pont, que lo havía comunicado con el Ayuntamiento i que los del Govierno estavan en malíssima disposición i arrestados a disputarme todos los trabajos, i que le parecía más conveniente el que yo cejara, que no llegar a pleito, pues con el pretexto de defender al Común, me pondrían en un laberinto. Hice reflección de que los que componen el Goviemo son los que fraguaron mi emulación, i que era mui posible llevassen adelante sus ideas maliciosas, por lo que me pareció condescender en ajustarme por medio del mismo Dotor Pont, quien lo ha egecutado mui a satisfacción de tal Villa, i con mucho detrimento mío. Dios lo ha dispuesto assí, paciencia. Por último habré sálido de tantas inquietudes i veré cómo sosegarme, que ya es liora.

Estimaré me haga Vm. el gusto de expresarle al S Dor Don Joseph Bermúrlez, que mi dependencia queda ajustada i Yo mui agradecido a su gran Lei i fineza, rle que le rindo mil gracias. I Vm. perdone mi molestia, con el seguro de que me cnmendaré en adelante no escriviendo cosa que huela a dependencia sí, con nuevo estilo, solicitando motivos de servir a $V \mathrm{~m}$. como ahora lo hago i ruego a Dios gar a Vm. ms.as. Oliva, i Abril 10 del 1734.

B.1.m. de Vm.

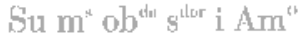

Miguel Egual

S'D" Greg Mayáns i Siscar mui S' mío.»

\section{XIII}

*Mui Stru nío, i amn. Por la que escriví a Vill. el correo passado, laalbrá cntendido Vm. quedar mi dependencia ajustada; haviéndome hecho ceder la Vio- 
lencia de la Oposición, i deseo de mi quietud. Todos conocen el agravio, que se me hace; pero en llegando al reme dio nadie le practica, tanto puede la ceguedad de la invidia. este correo, según me dice el Dr Pont, va conforme con el ajuste, i hasta aora no ha advertido, que yo devía firmarle, irá a su moda, i no le estará bien que yo le vea. Puede ser que ahí se repare.

Amigo yo lo he dejado a Dios, para ver, si sosegándome podré más bien servirle. Todo mi perjuicio viene a reducirse a unos ciento, o a lo más, 150 pesos; i según se explicava esta gente, tomando por pretexto el beneficio común, podían maliciosamente acarrearme 150 mil pesadumbres. Dios les haga mucho bien, i dé luz para governar con más justificación.

En mi antecedente supliqué a Vm. pasará esta noticia al S" D" Josef Bermúdez, Con mis rendidas gracias, por la fineza de sus oficios; pero este correo le escrivo directam bajo el mismo sentido.

He apreciado mucho el regalo de la efigie del $\mathrm{S}^{10}$ Christo; i he tenido especialíssimo gusto de leer los versos, que a más de su gran artificio; i concepto, son admirablemente piadosos. Por último son de $\mathrm{Vm}$. que es su mayor elogio. Doi a Vm. mil gracias, i siempre agradecido a lo mucho que a Vm. devo, ruego a Dios le $\mathrm{g}^{\text {tc }} \mathrm{m}^{\prime \prime} \mathrm{a}^{n} \mathrm{i}$ conceda $\mathrm{m}$ " felicidades. Oliva, i Abril 17 de 1734.

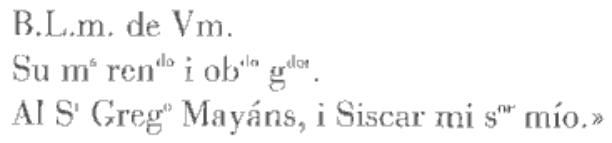

XIV

"Mui Sor i Am. mío después que salí de los trabajos que me acarrearon las persecuciones de Oliva (para mí más ingrata que el Cavallo de Glauco), resolví restituirme al retiro de mi casa, en donde me hallo con mi familia desde el día 6 del corr ${ }^{1 c}$ Aquí, i en qualquier parte me tendrá Vm. con la fina i constante lei que siempre. Esta Villa es algo menos racional que Oliva, pero lo que le falta de racionalidad, tiene más de libertad i quietud.

Yo me alentaré a ver, si puedo conseguir lo que Ovidio, quando le desterraron de Roma, transformándome en estos genios, si ya no es que para que no acaben de en mohecerse las potencias, buelvan a tentarme las Musas. Espero que por este conducto se servirá Vm. desinjuriar esta soledad con el alivio de franquearme muchas ocasiones de servicio, que Yo no dejaré de solicitarlas por el mismo, deseando siempre las más favorables noticias de la salud de Vm. y familia. 
Mi Par" saluda a Vm. con el acostumbrado afecto, i armbos roganos a Dios $g^{\prime \prime c}$ a V'". m a Pego, i Junio 17 de 1734.

\author{
B.S.m. de Vm. \\ Su más ren" i ob g gor \\ Miguel Egual \\ Sr D" Greg Mayáns i Siscar m.s.m.»
}

\title{
XV
}

"Mui S" i amigo mía. En el pasado recibí la favorecida de Vnu. de 3 del corr" con la espresión de la espectativa de la contaduría de la casa del señor Duque de Medinasidonia, a cuia fineza me confieso, i confesaré deudor eternamente; pues sólo la gran lei de VIn., i galantería del S" D" José Bermúdez pudieran acreditar mi cortedad con tan nobles impulsos. Pero laviendo hecho puntual reflección de mi positura, i apreciables circunstancias del empleo, me sirve de gran mortificación, no poder practicar aquello mismo, que apetesco, por hallarme con las luertes amarras de tres hijos, i mi Par en cinta: el mayor que es Antonio de diez años i de las dos Niñas, la mayor de vcho. Familia que totalmente embarazaria el trasplantarme en essa Corte, sino con gran incomodidad, i a mucha costa, i no acumulo mi edad do 53 años por hallarme con ardor, i espíritu para esse, i qualquier olro encargn Vm lo considere sin la passión, con que se esmera en favorecerme, que, tal vez, sentirá lo mismo que $Y_{0}$. No quisiera que $V_{m}$. legara a pensár que esto en mí es tibieza, o pusilaminidad de ánimo Valenciano, pues me acuerdo de la justíssima esclamación que VIn. hizo en la Dedicatoria al Eninentíssimo Fle'": O temporal o mores! Valentini qui quondam \&. Ginando sólo podían deteneme las referidas consideraciones. Pero si fuese tal mi fortuna, que los mismos favores de Vm, pudiessen dirigirse a las Conveniencias de este Reino, o de su Capital, en donde he pastulo la flor de mis años, con mis pocos estudios, hallaría cl corregimiento de ini deseo, i fácil salida a tanto repasso. En aquella hai muchos empleos, assí reales, como de la Inquisición, i de Geñores de essa Corte, que tienen sus Estados on este Reino, capaces para vivir con gusto, i conveniencia. si esto fuere dable In suplico a Vm. ya que directa" me hallo sin mérito para insinuárselo al 8 "Don Joseph Bermúdez, i sólo Vm. puede, como hásta aora, suplir mi demérito. Yo vivo bien seguro de que he de dever a $V m$. lo que solicito, i que mi obligación reconocida ha de emplearse siempre en lo que fuere de su mayor gusto, como en rogar a Dios g't i prospere a Vm. los mis as que deseo. Pego, i julio 24 de 1734 . 
B.S.m. de Vm.

Su más rend" i ob ${ }^{d x} s^{|t| r \mid}$

Miguel Egual

S' D" Grego Mayáns i Siscar in. s. 1n.»

\section{XVI}

*Mui $\mathrm{S}^{m+}$ mío, i Amº. Por el mismo conducto que ésta, ha llegado a mis manos el apreciable regalo, que a $\mathrm{Vm}$. le meresco, de las Cartas morales, militares, civiles, i literarias, que $\mathrm{Vm}$. ha recogido, i publicado. Han sido para mí del mayor gusto, assí por la variedad de asuntos, como por las muchas noticias, que incluyen. Ellas me sirven de único desahogo en mi frequente soledad, pues padezco el martirio de no tener con quien tratar cosa, que sepa a letras i estoi persuadido a que estos habitantes han hecho professión de aborrecerlas.

He tenido gran complacencia de ver en dichas cartas, egercitada nuestra lengua Española, con la pureza, dulzura, i eficacia, que ella tiene, i con especialidad (perdóneme Vm. ahora) en las de Don Nicolás Antonio i de Solís; pues el nervio de sus períodos, i propiedad de la lengua no dejan más que desear. Vm. ha empleado juiciosamente el tiempo en el trabajo de esta Obra, pues a más de haver manifestado en ella su profunda erudición, i dilatada noticia de los hombres doctos, se ha hecho, con notable usura, acreedor de todos. Yo he quedado corrido de leer mi nombre, con mi propria Naturaleza, i entre tantos literatos; pero moderé el sonrrojo, luego que hice reflección del aplauso, que a Vm. se le seguía de la discretíssima, i juiciosa Aprobación de las Declamaciones geniales, i este interés, en que tengo tanta parte, me ha sosegado de modos, que sólo no me queda la obligación de rendir a Vm. las gracias, como lo hago, por la buena memoria, que conservaré indeleble a fuer de agradecido.

Me ha dejado con la mayor satisfacción, el arreglado, i juicioso contexto de la Dedicatoria, i si el $\mathrm{S}^{\text {v }}$ Latino llegasse a egecutar la mitad de lo que Vm. le promete, tendría yo el gusto de passar por el gasto de ensanchar los estantes de mi pobre librería, como Vm. me dijo algún tiempo. Dios quiera darle los más eficaces impulsos, para que $\mathrm{Vm}$. logre con ellos el premio de sus fatigas, i los ascensos, que se merece, i yo tanto deseo.

Estos días pasados me mortificaron las balbucientes voces, de que $\mathrm{Vm}$. se hallava contrariado con Mánez; no supieron decirme el motivo, i esta especie me tiene con cuidado; pues no quisiera que vm. tuviera el menor disgusto, considerando, que para enemigo un mosquito es malo, i más en la Corte. Vm. se sirva no 
olvidame con las noticias de los progresus de sus Esperanzas; pues no puede dudar, que nadie con más afecto, que yo, cele brará sus adelantamientos, i si en este rincón puedo servír de algo, Vm. sabe mi obligación, amor, i reconocimiento. Mi p Jusepa se acuerda nuti de veras de Vm, encomendándole a Dios. La familia buena, i todos repiten sus memorias, deseando a Vm. las mayores felicidades, i yo siempre finam" de $\mathrm{Vm}$. ruego a Ds le gte mis as Pego, i Nove a 20 de 1734.

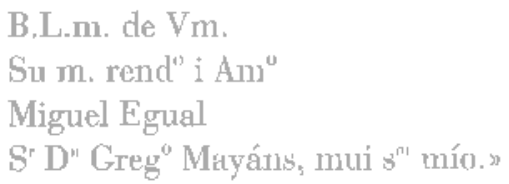

\section{XVI]}

«Mui S" mío. He tenido singular complacencia en la lección del libro de las Armas, i linages de España, con la Vida de D" Antonio Agrestún; pues en ambas obras hai mucho que aprender, i que admirar. i puedo asegurar a Vm. sin género de pasión, que para mi genio, me ha satislecho más la Vidá de D" Antonio que los Diálogos de éste, tal vez, será ignorancia mía. Lo cierto es que he quedado admirado de ver el juícioso artificio con que $\mathrm{Vm}$. la ha descrito, i creo que se hará venerar en todas partes. También devo al favor de Vm. la Disputa contra Vazques, que aunque no es e mi profesióm, he comprehendido bastan su contexto, i en el punto principal he admirtulo la claridad con que Vm. se ha sabido explicar; aunque el sentimiento es áspero, lo hace deleitable el artificio. Rindo a Vm. las gracias, y me repito mil enorabuenas, con las esperanzas de ver a Vin. premiado como sè merece, que será mi mayor gusto. Yo le tengo sicmpre que vm. me facilite ocasiones de servirle. Mi p Josepa saluda a Vm. linamen-

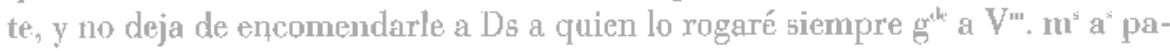
ra honra de nt" Reino. Pego, i Abril, 1 de 1735.

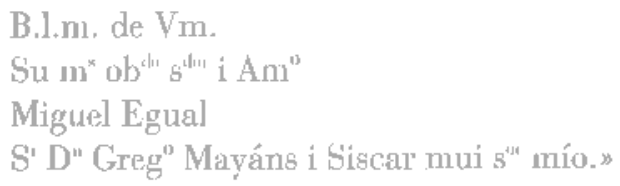

\section{XVIII}

"Mui S" mío. i Amigo. He celebrado con singular complacencia la honra con que el S'" Inquisidor Gen' ha premiado los méritos de su hermano de Vm. 
D" Manuel, mi Amigo i $\mathrm{S}^{\mathrm{n}}$, nombrándole Secretario con cgercicio de la inquisición de Valencia, eficaz argumento de lo mucho que Vm. sabe merecerse en essa Corte. Doi a Vm. la enorabuena i espero con ansia repetirla de la promoción de Vm. a empleo que se proporcione con su mérito, en que Yo tendré mi mayor gusto. Mi Par ${ }^{1 a}$ Jusepa hace la misma espresión a $V_{m}$., i no deja todos los días de encomendarse a Dio.

Quedo mui agradecido de las Reglas de Ortografía castellana de nuestro Maestro Antonio de Lebrija, refleccionadas por Vm. con tanto acierto. Yo deseava mucho ver esta ortografía, pues hablando de ella con Monseñor Vidanía, me dijo, que quando estudiava leyes en Huesca, la vio impresa i que después hizo varias diligencias por ella, i no pudo lograrla. He celebrado ver que sus principios i definiciones no se apartan de la Ortografía que Vm. practica, i me ha gustado mucho la Reflección sobre la C i la Qu pues Yo jamás he podido acomodarme a escrivir qual i quando con C, pareciendome que no alterando la pronunciación, escriviéndolas con que no devemos apartarnos de su imediata derivación, de donde, en mi sentir quedaron puras. $\mathrm{Vm}$. procure no darse tanto a la fatiga, que como lima sorda consume más de lo que se percibe, i deve haver algún rato de desahogo para tomar aliento. Yo vivo a lo rústico en este páramo, pero siempre con las constantes esperanzas de salir de él, i servir a Vm. en quanto fuere de su mayor gusto. $D^{\kappa} \mathrm{g}^{\text {ik a }} \mathrm{Vm}$. los $\mathrm{m}^{*} \mathrm{a}^{\mathrm{b}}$ Pego, i Abril 18 de 1735.

B.l.m. de $V m$.

su m, ob ${ }^{\text {the }} \mathrm{s}^{\text {sht }}$ i Am $^{\circ}$

Miguel Egual

$S^{r} D^{n}$ Greg" Mayáns i siscar mui $s^{n r}$ mío. o

\section{XIX}

"Mui S"ur mío i Am" La dependendia de Jábea, quedó concluida el día 18 del Corr" de que se autorizó cscritura pública de Concordia, la que procuré no fiar a la dirección de los Escrol de allí, sí que la trabajé antes de venirme. El ajuste se reduce a que el Clero ba de pagar desde luego 4250 , con más transferir a favor de Vm. todas las pensiones de los Censos, devengados asta la muerte de D" Antonio Gruañes, que fue en el año 1722. que importaría según computamos, algo más de 400 = Que el Clero ha de pagar todos los cargos de la herencia vencidos asta la muerte de su Sori tía Doña Laura que todos los bienes muebles que se hallaron en la casa i que a instancia del Clero se inventariaron, han de quedar de $\mathrm{Vm}^{*}$, que la esclava Catacumba, a quien dió libertad su $\mathrm{S}^{\mathrm{ma}}$ tía en el testamento, como si fuese propia, quede de $\mathrm{Vms}$, sin reintegrar al clero cosa algu- 
na por su estimación, i por fin comprehendo, que respeto de las dotes i Herencia de Dona Teodocia, importa el ajuste hecho a favor de Vm. unas cinco mil libras, sin lo que resulta libre de la Herencia de su S ${ }^{\text {ort }}$ tía $D^{a}$ Laura, que siempre será algo. Huvo a la Conclusión de este couvenio, pues el Cilero formó un papel, objetando los derechos de las Dotes, a que Respondí en el breve tiempo de dos horas; i comprehendimos que con la respuesta, se amainaron lus velas. Aseguro a $\mathrm{Vm}$. que a no haver dado en el tropiezo de que su Sira tía, quando entró en el Isufructo, no hizo inventario como devía; por precisa formalidad de derecho, apenas le huviera quedado al (ilero con qué fundar Administración pero este defeto (aunque defendi en mi respuesta, que no lo era atendidas las circunstancias que intervenian) nos atemorizó para el caso del pleito en que jamás consentí por saber sus consequencias. Por fin quedó, gracias a Dios, todo reservado; i el día 19 me restituí a esta Villa quedándose en la de Jábes Los ami i S D" Luis Larg` i D" Man' pasa practicar el cumplimiento del ajuste, admitir la he-rencia de su S $^{\text {u }}$ lía, a beneficio de inventario, i hacer este para resguardo en lo venidero. Yo quedo gustossíssimo de haver servido a Vm. en esto poco, i deseo otras muchas ocasiones para manifestar mi afecto, i obligación rendida. Iosefu,

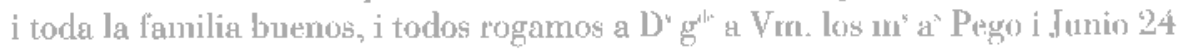
de 1735 .

B.],m, de, $V m$.

Su $\mathrm{m}^{5}$ ob , $^{\text {the }} \mathrm{s}^{\mathrm{d} r \mathrm{i}}$ i Amn"

Migucl Egua]

S' D" Grego Mayáns i Siscar mui S" mío.”

\section{$\mathrm{XX}$}

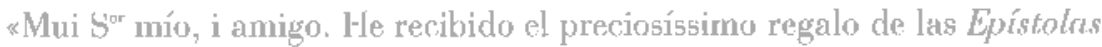
i Vidu de Don Mannel Martí, a que rindo a Vm. las devidas gracias. He empezado a leer la Vida, que por ser obra de Vm. es en mi estimación (la primera) i después sacaré lo que pudiere, pleses tengo hecho concepto que la profunda erudición de Martí, necesita de mucho estudio. He passado positivament" a Oliva a

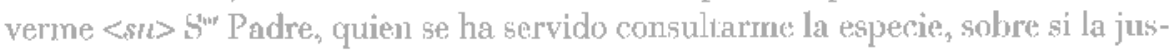
ticia ordinaria (en caso de faltar su merced) podrá hacer inventario de sus bienes conno lo hace de todos los que mueren sin excesivos costos, a que le he respondido, que siendo los herederos $V m^{b}$ y todos tres exentos de la jurisdicción Ordinaria, no podrá ésta por ningún pretexto ccharse sobre sus bieves, i assí lo siento con ln que me parece ha quedado sosegado su S ${ }^{\prime \prime}$ Padre.

Esperaré con impaciencia el éxito de la conveniencia de D" Juan Antonio, i 
quando llegue el caso la celebraré con el gusto que Vm. habrá comprehendido de mi fina ley. Mi Antonico ya empieza a construir Concilio, i Breviario, pero como es tan muchacho, que hará los doce años al Marzo que viene, hago cuenta de no estrecharle, pues tendrá tiempo para todo. Mi $\mathrm{P}^{\text {a }}$ saluda a Vm. y no se olvidará de encomendar a Dios, esas dependencias, i Yo en qualquier que Vm. me considere de algún provecho, me aplicaré gustoso a servirle, i siempre rogaré a $D^{s} g^{\text {ste a }}$ Vm. los m" a Pego a Noviembre 27 de 1735.

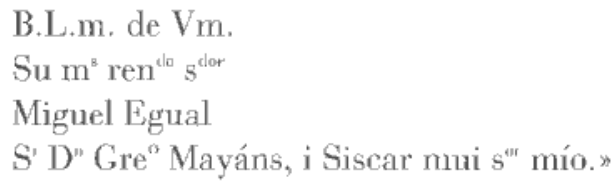

\section{XXI}

«Mui Sur mío, i Amigo. Deseo que Vmr. logre con la mayor felicidad, i alegría,

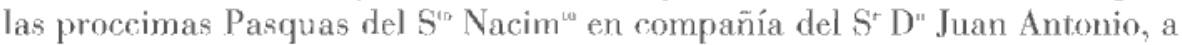
quien hago la misma espresión, i Vm. se servirá recibirla de parte de mi Para . i de Antonico, quienes saludan a Vm. con todo afecto, i con el mismo rogamos a Ds g't. as V'". m* a" Pego, i Dez" 16 de $1735=$

Aún passo mis buenos ratos, leyendo la Vida de D" Man. Martí i hago cuenta de leerla segunda vez para hacerme Dueño de ella.

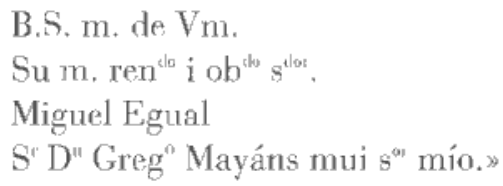

\section{XXII}

"Mui S $\mathrm{S}^{\text {er }}$ mó, i Amigo Deseo que Vm. logre felicíssimas Pascuas, assegurando a $\mathrm{Vm}$. las tendré mui alegres, como Vm. se acuerde de mandarme. Esta misma espresión ,se servirá Vm. recibir de parte de Jusepa, i de Antonio, quien ya empieza a vertir a Cicerón i para el Octubre que viene hago cuenta saldrá a Filosofía.

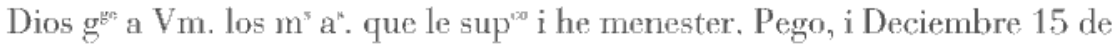
1736. 
rá esta una de las mayores i quedaré tan agrade cido como deseoso de emplearme en su mayor serv ${ }^{0}=D^{s} g^{\text {de }}$ a $V m$. los $m^{y} a^{s}$ que le sup ${ }^{c o}$ i ha menester Pego y Henero 251737 . En caso de lograrse la carta del $S^{\text {rw }}$ Fiscal venga bajo pliego mío, que yo la pondré en manos de mi sobrino.

B.l.m. de Vin.

$\mathrm{Sum} \mathrm{m}^{\mathrm{s}} \mathrm{ob}^{\mathrm{do}} \mathrm{s}^{\mathrm{dot}} \mathrm{i} \mathrm{Am}^{\mathrm{n}}$

Mignel Egual

S' D" Grego Mayáns, i Siscar, m. s. M.»

\section{XXIV}

"Mui s" mío. Deseo a Vm. la más cabal salud, i ofresco la que desfruto con toda mi familia al servicio de $\mathrm{Vm}$. con inmutable aft".

Por medio de su S" Padre he logrado la discretíssima Declamamación o Carta que Vm. escrivió al $S^{60} D^{\prime \prime}$ Fran ${ }^{(0)}$ de Almeida sobre la sentida muerte de D" Manuel Martí at" Paisano i con justa razón mandó imprimirla, pues a más de havernos Vm, eternizado con ella, la memoria de tan gran sugeto quedarán los Doctos, i aún del Vulgo, enterados de su noticia, ya que la sepultó la ignorancia, común desvío de estos siglos infelices.

Antes de ayer supe la promoción del $\mathrm{am}^{\circ}$ i S $\mathrm{S}^{\text {or }} \mathrm{D}$ " Joseph Bermúdez a Alcalde de Corte, i este Correo le escrivió la enorabuena, acordándole mi oblig"; i pues Vm. sabela que tengo de servir a Vm. no me olvide i mande, mientras ruego a Dios g $g^{\text {th }}$ i prospere a Vm. quanto deseo, i ha menester. Pego i Agosto 16 de 1737.

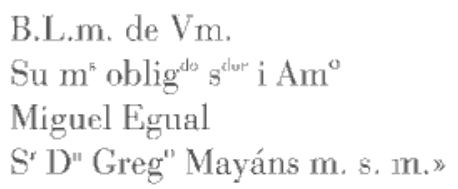

\section{XXV}

«Mui s" mío. Acuerdo a Vm. mi rendida oblig" con el Anuncio de las Pasquas del Nacimiento del hijo de Dios, que deseo consiga Vm. con la mayor felicidad. Yo espero lograrlas igualmente festivas, como Vm. no se olvide de mandarme $q^{\text {th }}$ fuere de su servi".

Am", he tenido gustosíssimos ratos en la lección de Veranio sobre el Diario, aunque me ha hecho notable falta el Orígenes de la Lengua Española de 
Vm. que sólo he visto en Gareta, i si huviesp ocasión apreciaré mucho no quede defraudada mi Biblioteca de esta obra, mayormente siendo de la Lengua Española a quien soi, i he sido tan amante, i deví muchas noticias a Monseñor Vidaria y a sus libros. Este eruditíssimo Aragonés tenía trabajada una Disertación para el principio de su diccionario, llena de noticias del mayor aprecio, i decía que Aldrete havía dado mucha luz de la lengua Española pero que le faltaron las noticias más radicales. Lo cierto os que el Triunvirato de los Diaristras vienen bastante que mascar con Veranio, i no será fácil que puedan digerirlo. Vm.

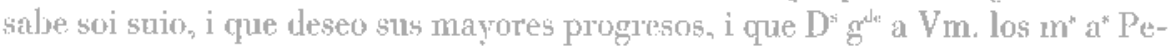
go, i Dez" 20 de 1737.

$$
\begin{aligned}
& \text { B.L,m,de Vm. } \\
& \text { Su ms oblig } \text { s }^{\text {dor }} \text { i Am } \\
& \text { Miguel Egual } \\
& \text { S' D" Greg }{ }^{\circ} \text { Mayáns, m. s. m.» }
\end{aligned}
$$

\section{XXYI}

«Mui sur mío i $\mathrm{Am}^{0}$. Aunque retardada, he recibido la estimadíssima de Vm. de 20 de Dez" pasado, la que me ha dejado gustosíssimo, pues tanto tiempo, hace que no havía visto leura de Vm. Yo he librado a Vun. de la mortificación de las mías, por falta de salud, pues el año pasado padecí uná grave enfermedad en que me dieron por muerto, i la infinita misericordia de Dios, me libró de clla; ojalá sea para mejorarme en su S" scrvir. Me ha quedado una fuerte Destilación, que en llegando a destemplarme la cabeza, no puedo ver libro, ni pluma, Reliquia (según dicen) de mis desaprovechadas tareas; pero de qualquier forma puede Vm. asegurtrse que soi sinyo i que me satisfaze gustosamente en quto fuere de su servir.

Por aquí han corrido vozes de que Vm. ha obtenido licencia de su Maǵt pára veninse a la Paria pur espacio de un ario, lo que he oído con gran complacencia. Sup" a Vin me diga, si hai esperanzas de esto, para que Yo viva con las de bolver a ver a $\mathrm{Vm}$, que tanto deseo.

Mi Juan Antonio, no está tan aprovechado como devía, por la quiebrá de mi salud, pues me ha sido preciso retenerle en casa, hasta resolver solve su destino. El mío, por ahora es hacerlc Eclesiástico, sca cono fuere, i si él desea lo mismo, pues considero, que con este Estado, quedarán sus hermanitas más abrigadas, i mi Vejez, será más llcvadera. No dudo que en lo que Vm. pudiese contribuir a este intento me favorecerá como siempre. Mi Par ${ }^{1 \mathrm{a}}$ aluda a Vm, i no ces- 
sa de encomendarle a Dios, lo que ha egecutado mui de verás, desde que Vm. se fue a essa Corte i passamos algunos ratos hablando de Vm. siempre con los deseos de su mayor felicidad. Y ambos rogamos a D" guc a Vm. m". a" Pego i Henero 19 de 1739. Sírvase Vm. decirme algo del Razonador Eloquente.

\author{
B. L. m. de Vm. \\ Su m $\mathrm{m}^{\mathrm{s}} \mathrm{ob}^{\mathrm{der}} \mathrm{s}^{\mathrm{d} \text { or }}$ i $\mathrm{Am}^{\circ}$ \\ Miguel Egual \\ S" D" Greg" Mayáns i Siscar mui Sc mío.»
}

\title{
XXVII
}

"Mui s mío. A Roque Girau tenía mui encargada la noticia del arribo de Vm. a esa Villa, para ir en persona a dar a Vm. el bienvenido, i cumplir el deseo de verle; pero la tuve a últimos de la semana passada, que por haver sobrevenido el alojamiento de dos Compañías de Cavallos en esta Villa, de quien soi secretario, no he podido egecutar mi viaje. Me desprenderé de la precisión de estas ocurrencias, i acudiré a mi obligación, i entretanto reciba $\mathrm{Vm}$. de mi verdadero afecto el bienvenido, en compañía del s' $\mathrm{D}^{n}$ Juan $\mathrm{Ant}^{\circ}$, a quien hago la misma expresión, celebrando el arribo de $\mathrm{Vm}$. a sus Patrios Lares, i al Julius amor Patri \& i con esta proximidad espero, he de tener muchas ocasiones, en qué servir a $\mathrm{Vm}$.

Hanme dicho algo de la insigne librería que Vm. ha traído, i aunque Yo apenas conosco los libros por mi ignorancia, no dejaré de tener mucha complacencia en verles. Vm. mande, que ya sabe soi suyo de corazón $D^{s} g^{d e}$ a Vm. los $\mathrm{m}^{\mathrm{s}} \mathrm{a}^{\mathrm{s}}$ Pego, i Agosto 19 de 1739.

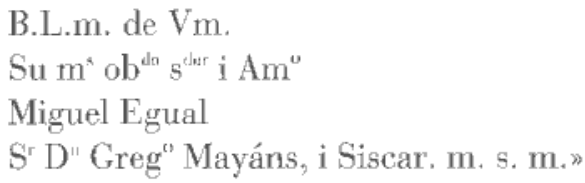

\section{XXVIII}

"Muy s"' mío. Por muchas circunstancias no puedo dejar de celebrar su pensamiento de Vm. en la premeditada elección de compañera sobre que hablaremos, quando nos veamos. I respeto de mi ida a ver essa librería que tanto deseo, atendidas mis ocurrencias, la resuelvo para el miércoles, que contaremos 
16 del corr' en que podrá venis la cavallería (que admiro su ceremonia, porque aquí no hay de qué echar mano) tan de mañana como pueda venir, para librarme del calor, i lo mejor será avisar a Roque Girau, para que me remita su Haca, i Criado, por ser su Cavallería segura, i Yo ser mal Gavallero, lo que prevengo para que en todo caso, no tengamos tropiezo. Todo lo demás será quando nos veamos, pues ya sabe $\mathrm{Vm}$. $\mathrm{q}^{\text {in }}$ deseo servirle, como que $\mathrm{D}^{4} \mathrm{~g}^{\mathrm{du}}$ a $\mathrm{Vm}$. $\mathbf{m}^{5} \mathrm{a}^{\mathrm{s}}$ Pego, i sette. 13 de 1739 .

$$
\begin{aligned}
& \text { B.I.m.m., de Vm. }
\end{aligned}
$$

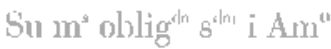

$$
\begin{aligned}
& \text { Miguel Egual } \\
& \text { S D" Gre Mayáns m. s. m.» }
\end{aligned}
$$

\section{XXIX}

"Mui s" mío, i Am" V a. mi Juan Antonio, a que su Sir Padre de Vm, firme la últina obra que hizo; con lo que $\mathrm{Vm}$. quedará libre del cuidado en que podía constituirle la falta de esta precisa formalidad, i Yo con el gusto de que Vm. quede enteram "s servido.

Al Muchacho, si Vm. gustare, se le podrá enseñar la librería por defuera, que es lo que permiten sus años, i se restituirá desde luego a Casa. Saludo a sı $s^{r}$ Padre, i a su Am D" Juan Ant i ruego a D. g g a V"'. $\mathrm{m}^{\mathrm{s}} \mathrm{a}^{\mathrm{s}}$ Pego i sette 21 de 1739.

$$
\begin{aligned}
& \text { B.l,m. de Vm. } \\
& \text { su m. oblig" S"r i Am". } \\
& \text { Miguel Egual } \\
& \text { S' D" Grego Mayáns, i Siscar.» }
\end{aligned}
$$

\section{$\mathrm{XXX}$}

«Mui s" mío. Hago memoria a Vm. de mi fina constante lei, con el Anuncio de las Pasquas del S' Nacimiento del hijo de Dios, los que deseo, conceda a Vm. colmadas de felicidades en compañía de su $\mathrm{S}^{\prime \prime 2}$ Padre i de mi $\mathrm{Am}^{\mathrm{n}}$ i $\mathrm{S}^{\prime} \mathrm{D}^{\prime \prime} \mathrm{Juan}$ Antonio a quienes repito esta misma expresión, i con ella suplico a Vm. se sirva no olvidarme de mi verdadera obed ${ }^{a}$ egecutándola en quanto fuere de su mayor servicio.

D" gle a Vm. los $\mathrm{m}^{5}$ a $^{6}$ Pego i Deciembre 29 de 1739. 
B.l.m. de $V m$.

Su mob ob stiter i Am"

Miguel Egual

Sr D" Greg ${ }^{\circ}$ Mayáns i Siscar mui S' mío.»

\section{XXXI}

"Mui S. Mío i mi Amigo. Anunciar a Vm. las Pasquas del Nacimiento temporal del hijo de Dios, es acordar a Vm. mi fina constante ley con los Vivos Deseos de que $\mathrm{Vm}$. las logre colmadas de felicidades en compañía de mi S su $\mathrm{P}^{\text {ta }}$ su $\mathrm{S}^{\text {or }}$ Padre, i D" Juan Antonio, a quienes repito esta expressión, i lo mismo egecuta mi Par ${ }^{10}$ con especial afecto. esperando entrambos muchas ocasiones de servir de Vm. cuia Vida rogamos a D" $\mathrm{g} \mathrm{m}^{3} \mathrm{a}^{*}$ Pego i Dez" 22 de 1740.

B.l.m. de $V_{m}$.

Su mºb ob $^{\text {(h) }} \mathrm{s}^{\text {thl }}$ i Am"

Miguel Egual

S D Dreg $^{\circ}$ Mayáns i Siscar mui S' mío.»

\section{XXXII}

"Mui s ${ }^{\circ r}$ mío, i $\mathrm{Am}^{n}$. Desde este rincón, apenas logro noticia alguna, ayer tuve la del feliz alumbramto de mi $S^{\text {ura }} D^{\mathrm{a}}$ Margarita Antonia, de que doi a Vm. la enorabuena, con indecible gusto; Yo deseo a Vm. fecunda sucessión. para que haya quien herede las riquíssimas potencias de que ha dotado $D^{* a}$ a Vm. ; i respecto de la recién nacida, sólo diré, lo que Vm. a Don Felipe Bulifón, en otra tal ocurrencia.

Quam bene socraticam tractas Pater optimus autem, fricum

Tam facili fusum pollice verset ea. Yo, con mi accidente, lo passo con algún trabajo; pero de qualquier forma siempre finíssimo de $\mathrm{Vm}$. Cuia Vida Ruego a Ds $\mathrm{g}^{\text {the }} \mathrm{m}^{\mathrm{b}}$. $\mathrm{a}^{\mathrm{s}}$. Pego, i Deciembre de 1741.

B.I.m. de $\mathrm{Vm}$.

Su mob ob $s^{\text {dor }} \mathrm{i} \mathrm{Am}^{\circ}$

Miguel Egual

S'D" Greg Mayáns i Siscar mi S' mío.» 


\section{XXXITI}

«Mui S"w mío, i mi Amigo. Haviendo tenido la noticia de que D" Domingo de Bustos estava inclinado a dar a pensión el Beneficio que tiene en la Iglesia de esta Villa, con la esperauza de obtener no sé que Conveniencia, resolví encargar a su tío de Vm. D" Pedro Pasqual, mi amigo y $\mathrm{S}^{\mathrm{n}}$, hiciera con eficacia estu diligencia, para ver si podíamos hoptar este Beneficio, para mi Juan Antonio, que tanto lo deseo i me conviene. Egecutolo assí i se ha explicado Bustos, que, como se le facilite el obtento de una Capellanía Regular de las Galeras de España, nos preferirá a qualquier otro en dicho Beneficio, que quien maneja el Almirantazgo por donde corren las dependencias de las Galeras es el S" D" Joseph del Campillo, i que éste es lectura del S $^{0 r}$ Marqués de la Compuesta a cuia insinuación tiene por seguro el logro. Con este supuesto, llegó el casso, en que espero merecerle a Vm. la confiada protección, que siempre le he merecido, para que una vez enterado de todo, me favoresca en que al S" D" Joseph del Campillo, con lo que tengo por seguro el éxito. Incluio la carta de su vío de Vm. D" Pedro para que Vin. quede fácilmente enterado de todo, a más de que yo le supp" se abrque con Vm. para conferir sobre esto, i acordar la disposición que pareciese nás conveniente ya que Yo por mi Destilación i variedad del tiempo no puedo emprender camino; pues sólo voi a Misa i me Retiro. Espero confiadam". ie Vm. este l'avor, pues de él dependen mis Converiencias que sicmpre à estado en que â Vm. las havía de dever. Mi P* Jusepa hace humildem". la misma súplica; i ambos rogamos a V. gr a V'n m a Pego y I-Hen" 3 th 1742.

B.I.m. de Vm.

Su mºb $\mathrm{b}^{\text {ik }} \mathrm{s}^{\mathrm{lbr}}$ i $\mathrm{Am}^{\mathrm{O}}$

Miguel Eigual

S' D" Greg" Mayáns i Siscar mui S' mío.»

\section{COPIA DEL MEMORIAL PRESENTADOA SU EX' SENONA.}

"Miguel Egual, Ess"'"' Vecino do la Villa de Oliva, puesto a los Pies de V. Lx" con el rendim" que deve, representa: que con Carta orden, que se sirvió V.E. escrivir al Ayunt.". de esta Villa, con fecha de 28 de Febrero 1733 se dignó V.e. mandar, que el supp ${ }^{\text {lv }}$ se empleasse en hacer la liquidación de fechas, y recibo de Receptoría que responden los Vecinos de aquella, terióndose respeto a los salarios que havía llevado, por los Encargos que havía egorcido de Secretario, y Contador, y tue la Villa se ujustasse al Supp"en el tanto que se havía de dar por todo. Y deseando no tener que contravertir con la Villa cxpressó que, des- 
de luego, se emprendiesse el trabajo de dicha liquidación, que era su devido obedecimiento, y que, por todo lo demás lo dejara a la justificada comprehensión de V.e. y, haviéndose hecho elección de Amanuense pá lo material de este trabajo, le empezó el sup", con assistencia de Roque Salelles el día nueve de Mayo del mismo año, y a la infatigable aplicación de nueve Meses, sin excusar género de trabajo, se ha conseguido una exacta liquidación de los hechos, con confessión de cada uno de los Vecinos, con la mayor claridad, y sin la menor alteración, haviéndose en todo observado la forma prevenida por $V$. e. y el supp ${ }^{\text {te }}$ llevado al Cuerpo de la Obra, y su disposición, que queda en tres distintos Padrones, correspondientes a las tres fechas, Francas, Garrama, y Receptoría. Y deviéndose en esta obra (como V.e. manda en la Citada Carta Orden) tener respeto a los Salarios exigidos por el supp" parece igualmente justo, que con ella, se atienda a lo que extraordinariamente tiene trabajo por la Villa en el tiempo de sus empleos, por lo que representa a V.e. que en el año 1726 formó un Plano de todos los Propios y Ventas de la Villa, con sus cargos, y Obligaciones, que se remitió a V.e. para ver los fondos, que faltavan, a fin de cumplir con la concordia. Que en el año 1728 con asistencia de liquidadores nombrados por el Ayuntamiento trabajó en una liquidación de las Deudas atrasadas con la expresión de año por año, y que consideravan más exigibles ocupación que duró más de tres meses. En este mismo año trabajó un Resumen de todas las haciendas de los Vecinos, deduciendo los cargos de justicia, para facilitar la expedición de los Repartim ${ }^{105}$ de Contribuciones Reales, que por faltar de esta diligencia se hacían trabajos a mente.= En el de 1729 en virtud de la sentencia, que se dio en el pleito de la querella sobre la Demanda trabajó el supp" una Recopilación de todas las Deudas atrasadas desde el principio de la passada guerra, hasta el año 1725 inclusive, en cuio trabajo se ocupó con Amanuenses suios cerca de quatro meses. Y en el mismo pleito, para la defensa de los Goviernos, y Común de la Villa, libró 29 testimonios, así de sus cuentas y fondos, como de las Deudas de atrasos, los quales testimonios, según consta por los mismos Autos comprehenden 117 fojas, que sólo a razón de 68 cada una, que es su regular derecho, importan $35828=$ En el año 1730 trabajó un libro de los Censales que responde la Villa, que apenas se podía venir en conocimiento de sus Acreedores. = Ln este mismo año por orden que tuvo la Villa de la R'. Intendencia hizo un Padrón de todos los Capitales de las Haciendas de cada Vecino, llamándoles uno por uno a la Sala Capitular, con expresión de sus Ventas, utilidades, y Cargos de Justicia, Guia ocupación, con asistencia de expertos, duró cerca de tres meses, sin otros trabajos, que por no molestar a V.e. omita el supp" y todos a más de los que consigo han llevado los Encargos de Secretario y Contador: como son Ayuntamientos, Cuentas de todo género de Caudadales, libros de Repartimientos, libranzas, continuos alojamientos, y peculiares de sus empleos, y por esso, computables en su salario. 
Ha servido el supp a la Villa en virtud de Decreto de su Ex ${ }^{\mathrm{R}}$ al Exmo $\mathrm{S}^{\mathrm{x}}$ Duque, dado en 26 de julio 1725. y con el Salario de 100 al año, desde 8 de Abril 1725 asta el íltimo de Deciembre 1730 que son cinco años, ocho meses, y veinte y tres días, y después hasta fin de junio del año 1731 por cuio medio año sólo se Destinaron por orden de su Ex 20 las que aún no se le han pagado, ni 687 que se le devían de atrasos. Y siendo la juntificada intención de V e. el que la villa se ajuste con el supp ${ }^{\text {to }}$ en el tanto que se le deve dar por toda, havido respeto a lo exigido, lo ha dejado el $\operatorname{supp}^{10}$ a la disposición de Ve, bien seguro de que se atenderán sus trabajos, que se tendrá presente, que su Antecesor, que lo fue Pedro Juan Climent, gozó por los mísmos encargos de 70 de salario al año, sin dejar su cassa, y modo de vivir como el supp ${ }^{t e}$ le tenía en la villa de Pego, y que este ha egecutado con la mayor exactitud, quanto V.e. se ha dignado mandarle. Por tanto:

A V e. pide, y suplica se sirva dar la providencia, que más fuere de gusto, y servicio de $\mathrm{V}$ e. pues de qualquier forma, que el supp": sea atendido, siéndolo por v. e. se dará por satisfecho, assí lo confía del experimentado zelo de V.e. et licet.

Altisimus. \& ${ }^{n}$, 
EPISTOLARIO

ANTONIO EGUAL - GREGORIO MAYÁNS

CRONOLOGÍA DE ILAS CIARTAS

\begin{tabular}{|c|c|c|c|c|}
\hline$A . ?$ & DA & Mlits & AÑO & SK:NATURA \\
\hline I & 30 & jumio & 1742 & 3963 \\
\hline II & 2.3 & julio & * & $3902 * *$ \\
\hline III & $1+$ & agosto & 1764 & 3904 \\
\hline IV & . & , & , & 3965 \\
\hline V & 17 & . & , & 3960 \\
\hline
\end{tabular}

La carta señalada con ** procedr de Valencia y las demés de Pego. Todas pertencen a la Biblioteca Serrano Morales.

"Muy S" mío: Post salutem Passo a decir a Vm. cómo el Jueves 28 de los corrientes passó a mejor vivir mi Padre, i Señor con el común sentimiento que Vm. puede discurrir, sin perder de Vista el mío, de la Madre y demás familia; pero con el Consuelo de haverme dicho estuviera a sus pies en quantas ocasiones fuera de su mayor servi" le mitigue sólo con saber tengo de servirle.

Encargome dixera a Vm. no perdiera de Vista el negocio de Bustos y en el interim passara a essa Villa a Casa del Anigo Roque Girau a practicar que estando en éssa, podía más seguramente servirle. Y con este motivo quedo deseoso de le servir con la más fina voluntad en el interim que la Divina próspera a $V^{m}$. m a*. Pego y Junio 30 de 1742.

B. L. M. de Vm.

Su más afecto servidor

J" Antonio Egual

S D" Gregorio Mayáns y Ciscar.»

II

«Muy S. mío. Día primero del corriente entré en Casa del S ${ }^{o r}$ Ventura Cantó el número, y muy práctico, en la que espero Vm me mande en quanto fuere de su mayor servicio. 
A mi $\mathrm{S}^{\circ}$ Don Antonio hermano de $\mathrm{Vm}$. saludos, que no deje de mandarme, pues es cierto estar prompto para quanto se le ofresca. Y con este deseo quedo rogando a Dios guarde a $\mathrm{V}^{\mathrm{m}} . \mathrm{m}^{\mathrm{s}} \mathrm{a}^{\mathrm{s}}$. Valencia, y julio 23 de 1743.

B.l.m. de Vm.

Su más afecto servid.

J" Antonio Egual

Sr D" Greg ${ }^{0}$ Mayáns i Siscarm. s. m.»

«Muy Sor mío y Amigo. Recibo los 3 sellos primeros y, desde luego, me dedico a servirle.

Quedo con Rosa esperando sus órdenes y rogando a $\mathrm{D}^{\mathrm{s}}$ le $\mathrm{g}^{\mathrm{de}} \mathrm{m}^{\mathrm{k}} \mathrm{a}^{\mathrm{s}}$. Pego y Agosto 14 de 1764 .
B.L.M. de Vm.
Su más aff" Sor y Amig.
Juan Antonio Egual.
S' D" Gregog Mayáns.»

* Muy Sr Mío y Amigo. Recibo la de Vm. con la Vencración devida, y registradas las postrimeras voluntades de sus señores Padres (que gozan de Ds). Son preciosos sellos primeros 3 para las sacas, por haverse de duplicar la de mi $\mathrm{S}^{\mathrm{m}}$ D" Pasqual. El Rcceptor de esta Villa no tiene de esta clase, pues los 6 que sólo le dan para el año, ya fueron despachados antes de Mayo, según me acaba de dezir, y que esto mismo le ha sucedido otros años. Por lo que hallo preciso que $\mathrm{Vm}^{\mathrm{d}}$. se digne mandar, remitirme, los 3 sellos primeros, ya sea de essa Villa o de Gandía, que luego les reciba, seré puntual en obedezer. Quedando muy gustoso de tener esta ocasión para emplearme en Servicio de $\mathrm{Vm}^{4}$ cuya Vida g ${ }^{\text {le }} \mathrm{D}^{*}$ $\mathrm{m}^{n} \mathrm{a}^{\mathrm{s}}$ Pego y Agosto 14 de 1764.

Rosa, cuino el resto de esta su casa, no se olvidan de mil expresiones a todas Vmit, particularmente a mi $\mathrm{S}^{\text {ro }} \mathrm{D}^{\text {in }}$ Margarita. 
B.L.M. de $V m^{i}$

Su más $\operatorname{Seg}^{\text {ro }} \mathrm{S}^{o r}$ y Amº

Juan Antonio Egual.

S' D" Greg" Mayáns i Ciscar.»

"Muy Sr mío y Amigo. Remito las 3 Copias de las Ultimas Voluntades de sus $s^{\text {rex }}$ Padres mis s sex y por ser difuera la del s" D" Pasqual no se ha despachado con la brevedad que deseava.

No se hable de paga alguna, pues devo hazer gracia de $\operatorname{los}<>$ con cuyo espíritu certiliqué a continuación de cada saca quedará satisfecho; pues sólo tengo el interés y ansia de saber si acierto a servir a $\mathrm{Vm}$.

Todos los de esta su Casa muchas expresiones a todos los señores y servidores de essa. Yo particularmente deseo acreditar mi rendida obediencia.

$\mathrm{N}^{\circ} \mathrm{s}^{\mathrm{r}} \mathrm{g}^{\text {de }}$ a V'". m $\mathrm{m}^{\mathrm{s}}$. Pego y Agosto 17 de 1764.

B.L.M. de $V_{m}$.

Su más aff $\mathrm{S}^{\text {or }}$ y Amigo

Juan Antonio Fgual, $x$

\section{ANEXO \\ Prólogo de Miguel Egual a las \\ Declamaciones Geniales.}

"CASI toda la gloria cede en el Autor que se traduce, de que se deja comprehender, quan desinteressado sea el empleo del traducir. I aún por esto devió confessar aquel célebre traductor D. Gómez de la Rocha i Figueroa en la inmortal obra que tradujo del Conde D. Manuel Thesauro, que no era la del traducir la más gloriosa, pero que ni la menos difícil; porque trasladarse la alma al Autor, describiendo lo que escondidamente concibió en su idea, siempre se grangeó el timbre de ingeniosa fatiga. Esta Traducción que trabagé para engañar el ocio honestamente, es de las Declamaciones Geniales de Juan Francisco Loredano, aquel Noble Veneciano, que dejó gravada su inmortalidad en sus eruditíssimos escritos. No quisiera que me adulasses con las preciosidades que te ofrece; pues las deves a la vivacidad de su ingenio. En mí fue diversión lo que 
tal vez te parecerá tarea, pues desde mís tiemos años tuve propensión a los libros, i especialente a las buenas letras, acalorado de aquel (en mi sentir) sentencioso axioma del discretíssimo Gracián, en su Discreto, que dice: Tal vez apronecho más saber escrivir una carta, i acertar a decir una razón, que fodos los Bártulos i Baldos. Las dos declamaciones de Antonio Caracala, i Frime, las he omitido por más que sea lo mismo que quitarle a Virgilio el Jibro quarto, i haya corrido felizmente la plumta en bus lratucciones. Pero antepuse, como devo, mis Christianas obligaciones a la gloria de Traductor, i si Virgilio en sus Fueidas se excedió a si mismo, no menos Loredanos en las dos Declamaciones omitidas. Hice las Adiciones, sólo porque huvicra algo mío, i no mostrarme ingrato a los cristales que beví algún tiempo de la dulcíssima Hipocrene. Si fueres discreto, a buen seguro que me agradecerás esta vciosidad, pues enire los primores de cada Declamación, hallarás el modo de reprehender i el de persuadir con los retóricos colores, que sirven de noble armonía al concepto. La propiedad de la Lengua Espariola, si futres amante de ella, te hará más sabrosa la lectura, pues ha sido este el blanco de mi cuidado. Por último tu benevolencia solicito, i con ella tu provecho. Podrás increpar mis errores, pero no mi intención, que ha sido, i será siempre, de servirte. Vale.

\section{[DEDICATYRIA]}

\section{AL SEÑOR D. JOSEF}

Bermúdez, del Consejo de su Mag. su Fiscal en la Real Junta de Aprosentros, i Procurador General de los intereses del Sereníssimo

Señor Infante Don Carlos.

\section{* Señor mío.}

LAS Declamaciones Geniales del Noble Vereciano Juan Francisco Loredano han corrido hasta ahora con mucha cstimación; porque en ellas ha encontrado el festivo sales, el acre invectivas, el Cortesano galanterías, el Humanista alusiones, el Fílósofo sentencias. Como este libro, pues, tiene tantos atractivos, ha podido grangearse el aprecio de muchos. Por esso me atrevo a dedicar a V. S. la traducción que bice años ha de dichas Declamaciones, adicionadas con algunas cadericias, malas por mías. Si algún error he cometido (i con- 
fiesso que sí), ha sido aver engastado un diamante con tan bajo metal: aver, digo, traducido una elegantíssima obra tan rúdamente. Pero ahora procuro dorar bien este yerro con la buena elección de tan buen Patrono. Los que tienen noticias de V.S. (i, ¿quién ai en España que no las tenga?) de su gran literatura, i erudición, de su eloquencia, afabilidad, prudencia, i demás partes, que constituyen un Cavallero a todos visos grande, i digníssimo de singular veneración. Ya conocerán que mi error sólo ha sido de entendimiento, porque no alcanzo más: pero no de voluntad; pues acierto a elegir un tan grande Protector, no quales suelen pintarnos tal vez las Dedicatorias algunos Héroes fantásticos, desfacedores de tuertos, i enderezadores de libros contrahechos, quales suelen ser las traduciones; sino de tan generoso ánimo, que sabiendo mui bien (como tan juicioso, i advertido), que lo que yo ofrezco es casi nada, i en buen, o mal romance, un honesto desahogo de más serias tareas. Sin embargo V.S. estimará mi voluntad, i me ofrecerá ocasiones en que yo pueda manifestar el deseo que tengo de servir a V.S. cuya vida Dios nuestro Señor guarde, i prospere muchos años, como puede, suplico, i he menester. Oliva a 11, de Abril de 1731.

$$
\begin{aligned}
& \text { B.l.m. de V.S. } \\
& \text { Su más rendido servidor } \\
& \text { Miguel Egual. }
\end{aligned}
$$

\title{
JUCIO DE MAYANS A LAS DECLAMACIONES
}

\author{
JUCIO DE DON GREGORIO MAYANS \\ $i$ Ciscar, del Gremio, $i$ Claustro de la Uni- \\ versidad de Valencia, $i$ su Cathedrático del \\ Código de Justiniano.
}

$$
\text { M. P. S, }
$$

"HE leído con la atención que devia las Declamaciones Geniales, de Juan Franciseo Loredano, Noble Veneciano, las quales ha traducido en Español Miguel Egual, Escrivano real, añadiendo a cada una de ellas un Soneto propio. Para cumplir pues con la obligación que V.A. me ha impuesto, diré con libertad ingenua aquello mismo que siento. Diez i seis años tenía Juan Francisco Loredano, quando quiso egercitar su nobilíssimo ingenio en algunos asuntos. Como aquella edad es más florida, i los estudios suelen ser profanos; eligió asuntos por la mayor parte amorosos, introduciendo en ellos personas Gentiles. El deseo que tenía de guardar el decoro (primer precepto del arte) le hizo meditar, i después 
proscguir en boca de los êthnicos aquellas mismas sentencias, i espresiones, que juzgava el Autor que dirían ellos en semejantes casos. De aquí nace tan frequente mención de la disposición de los Hados, de la fortuna, i de los Dioses: espresiones de que tanto luyeron los Santos Padres antiguos, siendo assí 'pue vivian entre los mismos Gentiles, i que nos inculcan ahora muchos modernos, particularmente los Poetas, o porque inadvertidamente las beven en los libros de los Gentiles, o porque hacen alarde de parecer leídos, i tal vez piensan, que parecerá que igualan a aquellos en el arte si los siguen en esto, que es tan fácil de imitar. Puédense volerar los Gentilismos que escrivicron los que por desgracia suya hicieron de ellos professión, pero no los que repiten aquellos, que por su Religión Cihristiana los deven abominar. Con razón pues el Traductor hace una protesta juiciosa sobre este asunto. Fuera de esto, entre dichas Declamariones avía dos, es a saber, Antonino Caracula Amante, i Frine Lasciva, que pudieran ser a la juventud incauta, tanto más perniciosas, quanto nás ingeniosas i elegantes. Desechólas el Traductor Después de averlas vertido, anteponiendo las obligaciones Christianas a los aplausos que le pudieran resuliar de dicha versión. Las denás Deelamaciones, aunque sus asuntos no son usuales, quicro decir, absolıtamente prácticos (vicio común de este género de composición, de que se quejaron tanto en sus tiempos nuestro Español Quintiliano, i Petronio Arbitro) pueden sin embargo ser útiles a los Letores de seso, que sabrán distinguir lo juicioso de lo ingenioso: lo dice el Autor pidiéndolo la causa, i lo que se añade por afectar fecundidad. A lo menos no dudo que serán aceptíssimas a la mayor parte de los Letores por la multitud de sentencias, variedad de agudezas i novedad de espresiones. En lo que toca al Traductor, aunque soi annigo suyo, bablarí sin pasión. el trabajo de traducir es de los empleos peor agradecidos. El Autor se lleva los aplausos, el Traductor los oprobios. Como de la Pintura juzgan peritos, e imperitos, assí de las traducciones doctos, e indoctos. Las doctos, porque lo entienden; los indoctos porque en este respeto, no sueden serlo. Aquellos leen el original, i traducción; cotejan, i censuran. Estos hacen su crítica con menos trabajo. Como sólo saben la lengua en que se ha traducido, inmediatamente advierten qualquier estraño idiotismo. Al contrario. el qque araduce, como intcligente en el irlioma origiinal, embeverido en él, atento más al sentido, que a la espresión, tal vez se descuida en esta. Dejo aparte que no ai idioma que no tenga ciertas palabras más espresivas que las de otro qualquiera, i cjertos modos de decir mui peculiares. Por cuyas causas, críticos gravíssimos han llegrado a decir, que en las traducciones son inevitables los defetos. Cierto es, que los que son de este género a nadie deven culparse. I que sólo es reprehensible lo que está mal espresado, o por no alcanzar el verdadero sentido, o por trocarlo, o por no saber aplicarle la correspondencia devida de que es capaz la lengua en que se traduce. Decir yo que Miguel Egual de tal manera ha evitado todos estos 
escollos, que pueda prometerse no incurrir en la censura de aquellos severíssimos críticos, que a nadie perdonan, sería hablar con pasión. Negarle que su pluma fácilmente ha superado dificultades gravíssimas, sería injusticia. Una cosa diré mui seriamente: Dicen (i es cierto), que de la medida de un dedo se puede colegir fácilmente la grandeza de un Coloso. Esto tiene lugar en las obras materiales: pero suele engañar en las del ingenio. Infieran pues, otros, de esta traducción, quan bien posee Miguel Egual la Lengua Española, quan sentencioso es, i grave, en los Sonetos que añade. Pero Yo les aseguro, que su juicio, prudencia i singular destreza en arduíssimos negocios, son las prendas que más me admiran, a las que deven ser la medida de su gran habilidad. Siendo todo esto assí (según alcanzo), en orden a dar licencia para que se publiquen estas Declamaciones Geniales, puede V. A. mandar lo que sea de su agrado, i más no aviendo en ellas cosa alguna que se oponga a las Regalías de su Mag., i aviendo corrido el original sin tropiezo hasta el día de hoi por Italia, i España. Assí lo juzgo en Valencia a 28 de Marzo de 1731.

D. Gregorio Mayáns, i Ciscar:»

«CENSURA DEL R.P.Fr: JUAN SALVA,

Letor en Theología, Chronista de la Santa Provincia de San Francisco de Valencia: por comisión del mui ilustre Señor Don Josef de Rius, Presbitero, Dotor en Sagrados Cánones, Canónigo de la Santa Iglesia de Barcelona, i por el Ilustíssimo, i Reverendíssimo Señor Don Andrés de Orbe i Larreategui, por la gracia de Dios i la Santa Sede Apostólica, Arzobispo de Valencia, del Consejo de su Mag. i su Governador en el Real de Castilla en lo espiritual i temporal en la presente Ciudad i Diócesi, Oficial, Vicario, i Governador General.

M. I. S.

Obedeciendo a V.S. he leído con reflexión las Declamaciones Geniales de Juan Francisco Loredano, Noble Veneciano, las quales ha traducido en Lengua Española Miguel Egual, Escrivano Real, dando fin a cada una de ellas con un Soneto. Las Declamaciones descubren el genio e ingenio del Autor. El uno parece afectuoso i tierno, el otro fecundo i maravilloso. El Traductor se ha conformado con el original quanto ha podido, no sólo pensando, sino casi contando las palabras, cosa bien difícil de practicarse con acierto. La traducción manifiesta su gran habilidad, j lo mucho que ha trabajado en la Lengua Española. Los Sonetos son indicios de una noble vena Poética i, en su Género, son 
mucho mejores que las mismas Declamaciones por tener más peso en las sentencias i estar espressadas con mayor gravedad. Ha manifestado también el Traductor, quanto aprecia el cumplir con las obligaciones Cathólicas, aviendo quitado dos Declamaciones, que si bien havían corrido hasta ahora juntamente con las otras, no parecería decente que se İeyessen en Español. Mas quisiera decir del Traductor porque su mérito es mayor, pero quiero complacer a su modestia que me estimará que yo diga en su alabanza lo menos que pueda. Viniendo pues a mi propósito, estas Declanaciones se podrán imprimir, si V.S. concede la licencia que se pide. Assí lo juzgo en este Real Convento de San Francisco de Valencia, a 3 de Abril de 1731.

\author{
Fr. Juan Salvá, \\ Imprimatur \\ De Rius, Vic, Gen,
}




\section{BIBLIOGRAFÍA}

Beltrán Manrique, Enrique, Almazora. El Mijares. Narración Histórica, Castellón. 1958.

Blay Navarro, Juan, Documentos y datos para la Historia de la ciudad de Oliva, Valencia, Ecir, 1960.

Egual, Miguel, Cartas, en la Biblioteca Serrano Morales de Valencia (BSM): 7264-17 (A-15) de la 3967 a la 3998; y en el Archivo del Colegio del Patriarcha de Valencia (ABHM), en Gregorio Mayáns, Epistolario, libro VI.

Egual, Miguel (radictor de). Juan Franciseo Loredano, Dertrumaciones Geniales, su Autor, Noble veneziazo, Lu Valentia por Anouio Bordazar, 1731. Incluye los 22 sonetos. Biblioteca de la linversidad de Valencia $(\mathrm{BL} V): X-6 / 92$.

Egunl, Juan Antonio, Cartas. BSM: 7264-17 (A-15); 3962-3966.

Mas I Uso, Pasqual, "Miguel Egual, traductor i poeta», La Vila-roja, març, 1988.

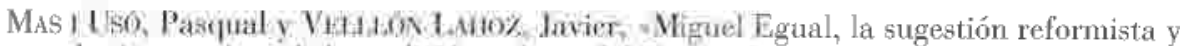
los imperaivos de la madicion . teres del Il congres d'historta i Filologia de la Plame. Nules, abrit de 1990, Nules, 1902, paigs, $1=19-161$.

Mestre, Antonio, El mundo intelectual de Mayáns, Valencia, Publicaciones del Ayuntamiento de Oliva, 1978.

Mundina, Fernando, Historia, geografia y estadística de la provincia de Castellón, Castellón, 1873.

XIMENo, Vicente, Fiscritores del heyno de Falencia Chronológicamente ordenados desde ol año MCСXXYHII de la Christima Conquista de la misma Ciudad, hasta el de MDCCXIII, Valencia, Esteban Dok, MDCCXL.VII. 